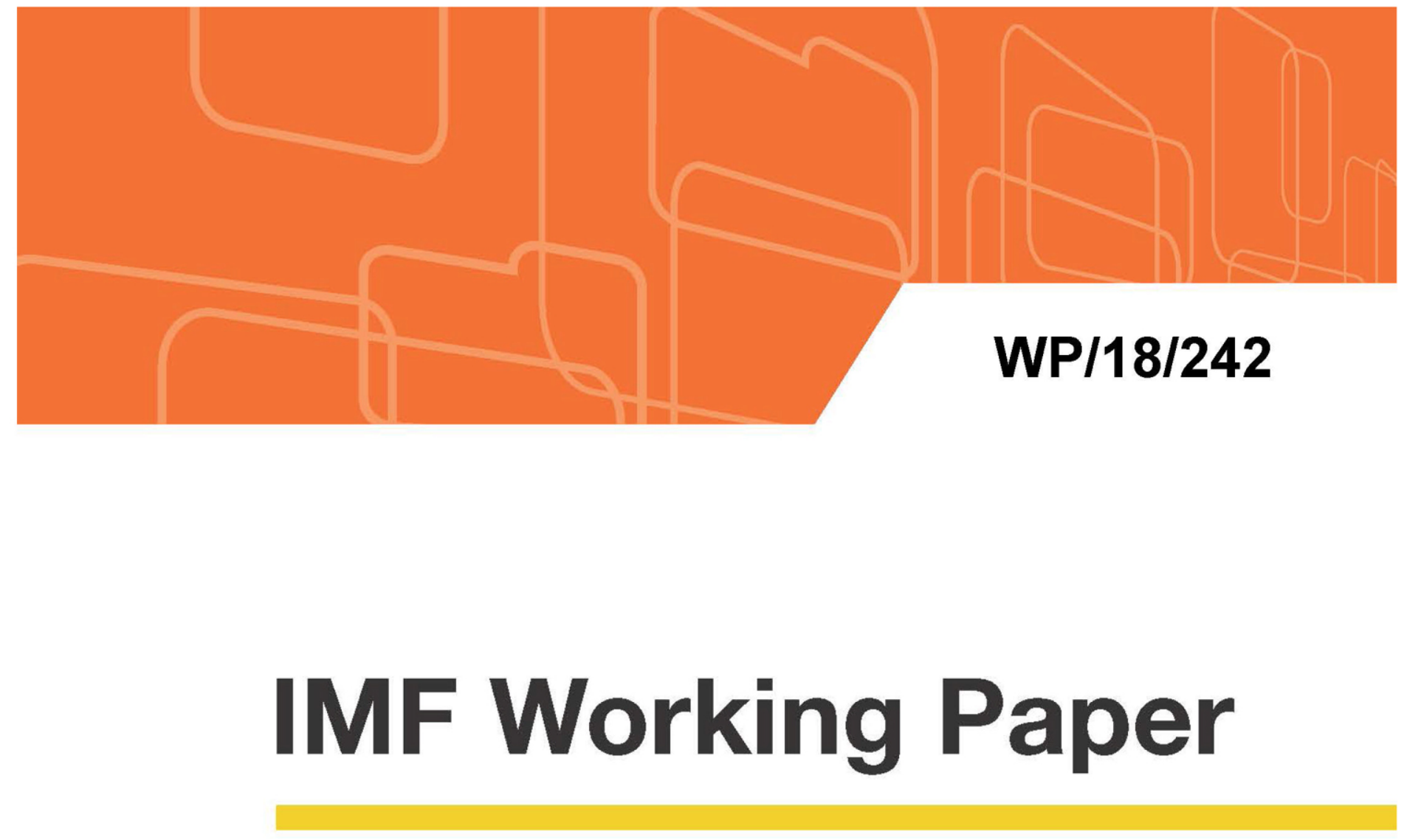

\title{
Equilibrium Yield Curve, the Phillips Curve, and Monetary Policy
}

by Mitsuru Katagiri

IMF Working Papers describe research in progress by the author(s) and are published to elicit comments and to encourage debate. The views expressed in IMF Working Papers are those of the author(s) and do not necessarily represent the views of the IMF, its Executive Board, or IMF management. 


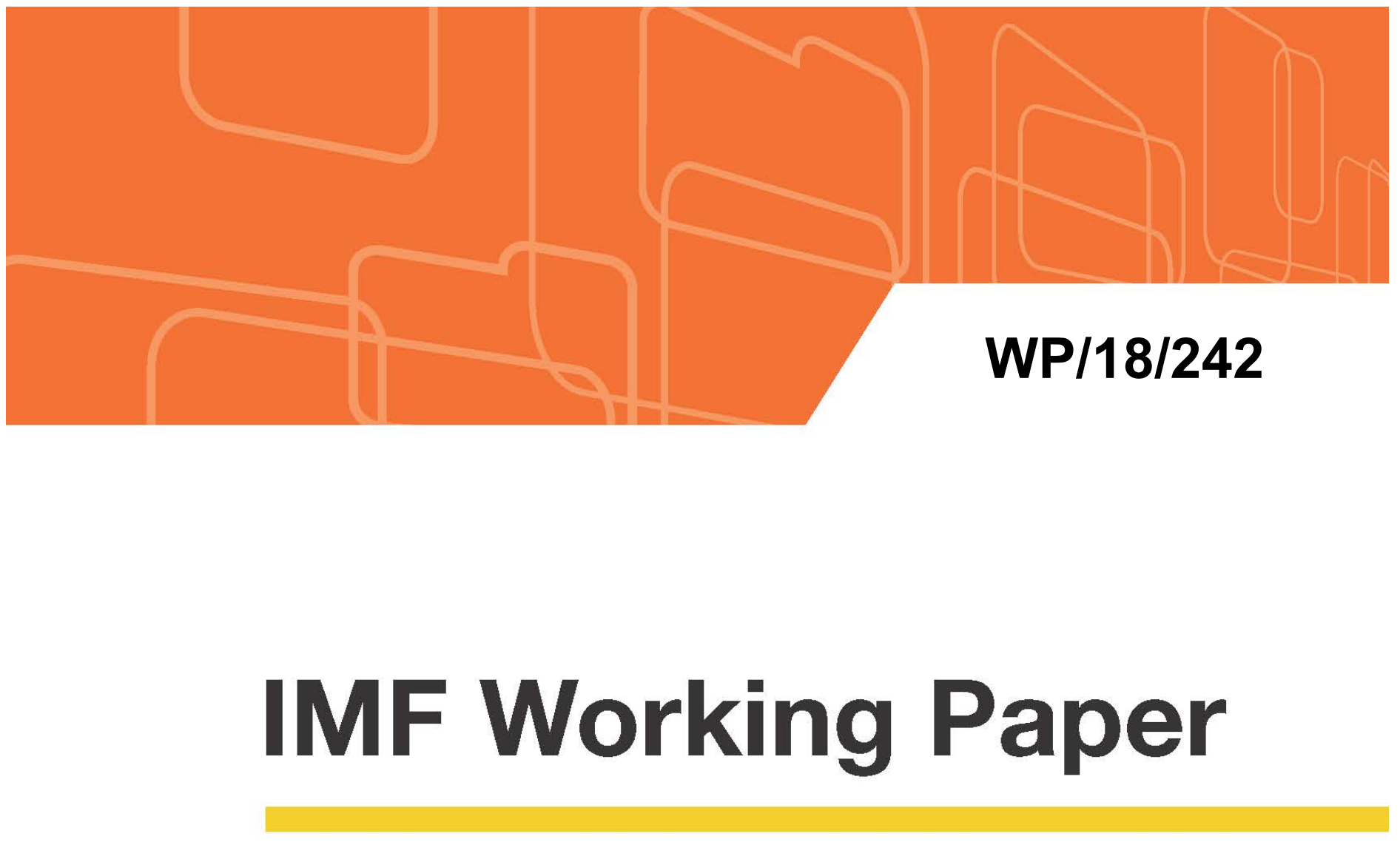

\section{Equilibrium Yield Curve, the Phillips Curve, and Monetary Policy}

by Mitsuru Katagiri

IMF Working Papers describe research in progress by the author(s) and are published to elicit comments and to encourage debate. The views expressed in IMF Working Papers are those of the author(s) and do not necessarily represent the views of the IMF, its Executive Board, or IMF management. 


\title{
IMF Working Paper
}

Monetary and Capital Markets Department

\section{Equilibrium Yield Curve, the Phillips Curve, and Monetary Policy \\ Prepared by Mitsuru Katagiri*}

Authorized for distribution by Claudio Raddatz

November 2018

\section{IMF Working Papers describe research in progress by the author(s) and are published to elicit comments and to encourage debate. The views expressed in IMF Working Papers are those of the author(s) and do not necessarily represent the views of the IMF, its Executive Board, or IMF management.}

\begin{abstract}
Upward sloping yield curves are hard to reconcile with the positive association between income and inflation (the Phillips curve) in consumption-based asset pricing models. Using US and UK data, this paper shows inflation is negatively correlated with long-run income growth but positively correlated with cyclical income, thus enabling the model to replicate positive and sizable term premiums, along with the Phillips curve over business cycles. Quantitative analyses also emphasize the importance of monetary policy, predicting that a permanently low growth and low inflation environment would precipitate flatter yield curves due to constraints to monetary policy around the zero lower bound.

JEL Classification Numbers: E43, E52, G12

Keywords: Term premiums, Phillips curve, Low-for-long

Author's E-Mail Address: mkatagiri@imf.org

\footnotetext{
* I would like to thank Francois Gourio, Taisuke Nakata, Hiroatsu Tanaka and staff of the International Monetary Fund for helpful suggestions and comments. I also appreciate the comments of seminar participants at the Federal Reserve Board and 2018 CEF conference. The views expressed here are those of the author and do not necessarily represent the views of the IMF, its Executive Board, or IMF management.
} 


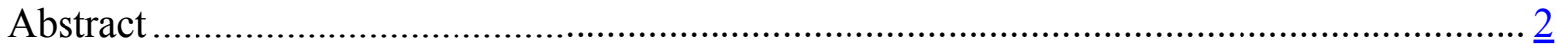

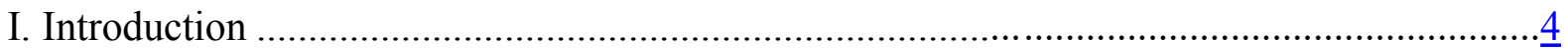

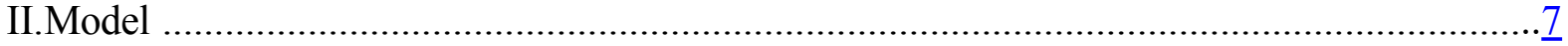

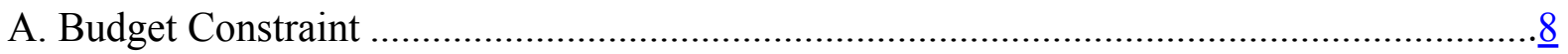

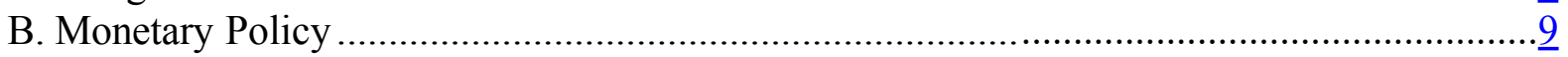

C. Household's Optimization and Equilibrium Yield Curve ............................................. 9

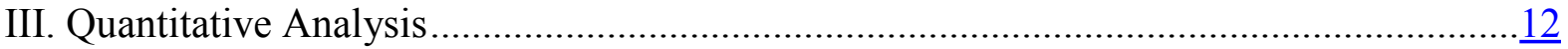

A.Estimation of Income and Inflation Process ............................................................ 12

B. Smulation Exercise for Term Structure of Interest Rates ........................................... $\frac{17}{25}$

C.Equilibrium Yield Curve in the Low-for-Long Economy .........................................

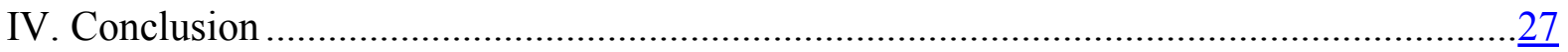

TABLES

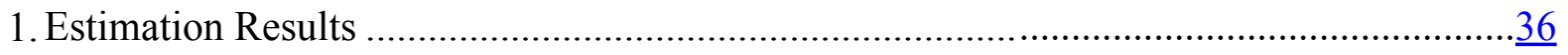

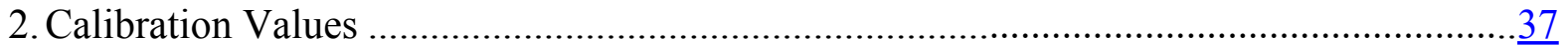

3. Stylized Facts: Shape of Yield Curves in the United States and the United Kingdom ..........38

4.Equilibrium Yield Curve in the United States and the United Kingdom ............................

5. Volatility of Nominal Interest Rate Relative to Inflation Volatility ............................... 40

6.Macroeconomic Moments for Consumption Growth ................................................ 41

FIGURES

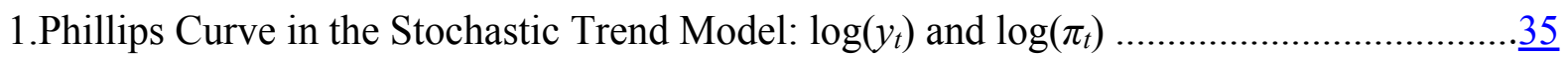

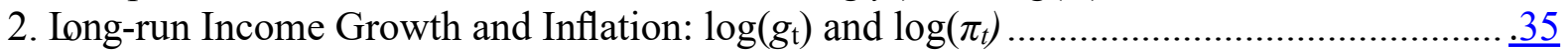

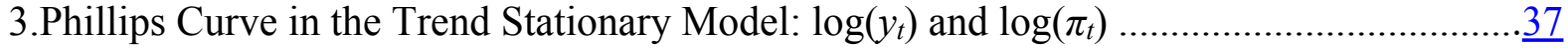

4.Equilibrium Yield Curve in the Simulated Model....................................................... $\frac{38}{39}$

5.Equilibrium Yield Curve with Different Monetary Policy Rules ..................................... $\underline{39}$

6. Relative Volatility for Each Maturity ................................................................. 40

7.Equilibrium Yield Curve in a Different Setting …...................................................

APPENDICES

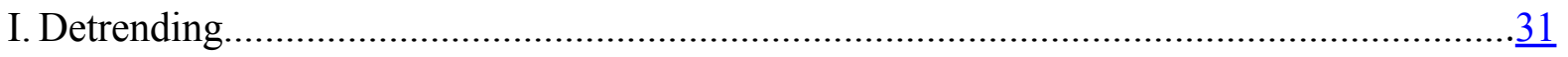

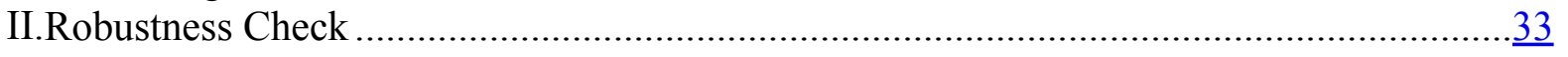

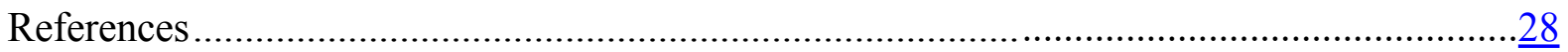




\section{Introduction}

Can we rationalize the shape of yield curves by consumers' optimal behavior? Since the shape of yield curves is characterized by risk premiums on long-term bonds (i.e., term premiums) on average, this question falls into the extensive literature to rationalize the level of risk premiums by consumers' optimization. ${ }^{1}$ Rationalizing term premiums is, however, somewhat more challenging than other risk premiums in several ways. First, since long-term bond prices are influenced by inflation, the model must be consistent not only with real economic activity but also with inflation dynamics and their co-movement with real economic variables. Second, the model must consider the policy behavior of central banks in addition to consumers' optimization because the short end of yield curves is entirely set by the central bank in most countries. In particular, since interest rate policies have been recently constrained by the zero lower bound (ZLB) under a low growth and low inflation environment in many advanced economies, understanding what the theory predicts about the equilibrium yield curve under such a policy constraint is a critical issue for policy makers.

This paper tries to address those questions by analyzing the equilibrium yield curve in a model with optimal savings as a buffer stock. In the model, consumers with the Epstein-Zin-Weil preference optimize their consumption path under an exogenous income and inflation process as well as nominal interest rates set by a monetary policy rule, and the equilibrium yield curve is derived to be consistent with consumers' optimization. The contribution of this paper to the literature is twofold. First, it shows that the shape of yield curves can be rationalized by consumers' optimization under the income and inflation process estimated by data. Specifically, the model successfully accounts for a realistic upward sloping yield curve in US and UK even under the positive association between income and inflation over the business cycle (i.e., the Phillips curve). Second, it shows that a monetary policy response to inflation is a key to accounting for the shape of yield curves. Given this importance of monetary policy behavior in shaping yield curves, a counterfactual simulation indicates that a permanently low growth and low inflation environment (the low-for-long economy, hereafter) would be associated with flatter yield curves due to changes in monetary policy behavior around the ZLB.

While term spreads in most advanced economies are positive on average, the positive term premiums are not easy to be theoretically rationalized under the empirically observed co-movement between inflation and real economic activity. A main takeaway in the previous finance literature

\footnotetext{
${ }^{1}$ The most actively investigated issue in this literature is the equity premium puzzle. For an extensive survey on this literature, see Cochrane (2017).
} 
is that, to theoretically rationalize the positive term premiums, inflation and consumption growth should be negatively correlated. To see why, let us think about the two-period nominal bond price, $Q_{2, t}$. Based on the Euler equation, it can be decomposed into the discounted value of the expected one-period bond price and the term premium,

$$
\begin{aligned}
Q_{2, t} & =\mathbb{E}_{t}\left(Q_{1, t+1} M_{t, t+1}\right) \\
& =\mathbb{E}_{t}\left(Q_{1, t+1}\right) / R_{t}+\operatorname{cov}\left(1 / R_{t+1}, M_{t, t+1}\right)
\end{aligned}
$$

where $M_{t, t+1}$ is the nominal stochastic discount factor (SDF). This asset pricing formula implies that the term premium is positive if the correlation between the reciprocal of nominal interest rates and the SDF is negative, i.e., $\operatorname{cov}\left(1 / R_{t+1}, M_{t, t+1}\right)<0$. Since the central bank increases nominal interest rates in response to inflation, the correlation between $1 / R_{t+1}$ and inflation has to be negative. Hence, given that the SDF is negatively correlated with consumption growth by definition, a negative correlation between inflation and consumption growth, $\operatorname{corr}\left(\pi_{t}, \Delta c_{t}\right)<0$, is necessary for $\operatorname{cov}\left(1 / R_{t+1}, M_{t, t+1}\right)<0$ and the positive term premium. Intuitively, if inflation and consumption growth are negatively correlated, long-term bonds become a poor hedge against a consumption decline because their prices decline in response to inflation, thus leading bond investors to require risk premiums. ${ }^{2}$

Although this argument in the finance literature does not contain any inconsistencies per se, a macroeconomic model with endogenous consumption usually faces difficulty reconciling $\operatorname{corr}\left(\pi_{t}, \Delta c_{t}\right)$ with one of the stylized facts in the macroeconomics literature, namely the "Phillips curve." While there are many variants of the Phillips curve in the literature, they basically establish the positive association between inflation and real economic activity including income, consumption, and employment over the business cycle, thus making it difficult for most consumption-based asset pricing models to account for positive and sizable term premiums under the empirically observed co-movement between inflation and consumption (the "bond premium puzzle"). Hence, a challenging but critical issue for the macro-finance literature is to account for the positive term premiums induced by the negative correlation between inflation and consumption growth, while preserving the positive association between inflation and real economic activity over the business cycle established in the Phillips curve literature.

This paper shows that decomposing the income process into a stationary and a non-stationary

\footnotetext{
${ }^{2}$ Given the negative correlation between consumption growth and inflation observed in most economies, some macro-finance models with exogenous consumption growth can account for positive term premiums (e.g., Piazzesi and Schneider (2007) and Bansal and Shaliastovich (2013)).
} 
part (cyclical income and long-run income) is a key to reconciling the arguments in the finance and macroeconomics literature, which appear to be inconsistent with each other. By estimating the income and inflation process using US and UK data, the empirical analysis indicates that inflation is negatively correlated with long-run income growth but positively correlated with cyclical income over the business cycle. Hence, since consumption is mainly driven by long-run income rather than cyclical income under the permanent income hypothesis, consumption growth is negatively correlated with inflation, thus leading to positive and sizable term premiums. Along with the positive and sizable term premiums, income fluctuations over the business cycle are positively correlated with inflation just because of the positive association between the stationary part of income and inflation, which is consistent with the Phillips curve literature. Those quantitative results are clear and simple but in contrast with the previous literature. For instance, Rudebusch and Swanson (2012) assume all variables are stationary in their model and account for positive term premiums by assuming the negative correlation between inflation and real economic activity over the business cycle, which is inconsistent with the empirical findings in the Phillips curve literature.

Finally, a quantitative analysis emphasizes the importance of monetary policy behavior to account for sizable term premiums observed in data. Given the importance of monetary policy behavior, this paper conducts a counterfactual simulation to examine what the model predicts about the equilibrium yield curves in the economy with permanently low growth and low inflation as argued by, for instance, the secular stagnation hypothesis. A counterfactual simulation via comparative statics shows that in the low-for-long economy, the equilibrium yield curve would not only shift downward but also significantly flatten mainly due to the changes in monetary policy behavior near the ZLB of nominal interests. ${ }^{3}$

\section{Literature Review}

This paper is closely related to the literature on the equilibrium yield curve in the consumption based asset pricing model. The early literature shows that replicating a realistic upward sloping yield curve is not easy under the empirically observed consumption and inflation process (e.g., Campbell (1986), Backus et al. (1989), Boudoukh (1993) and den Haan (1995)), and it is called the "bond premium puzzle." Subsequently, Piazzesi and Schneider (2007) replicate some key fea-

\footnotetext{
${ }^{3}$ As is discussed in IMF (2017), this result implies that the low-for-long economy may be associated with a higher financial stability risk due to the lack of bank profits adequate to build capital buffers, given that the maturity transformation is a main sources of banks profits.
} 
tures in the U.S. term structure using a model with the recursive preference, and Branger et al. (2016) investigates influence of the ZLB in a similar model. Those models, however, are difficult to be used for counterfactual policy analyses because they assume an exogenous consumption path. Another strand of this literature is the one that accounts for the shape of yield curve by a general equilibrium model with endogenous consumption (and inflation) (e.g., Rudebusch and Swanson (2008, 2012), De Paoli et al. (2010) Andreasen (2012), van Binsbergen et al. (2012), Dew-Becker (2014), and Swanson (2016)). Ngo and Gourio (2016) and Nakata and Tanaka (2016) are particularly related to this paper because they investigate the effect of the ZLB of interest rates on risk premiums. Compared to this strand of research, the present paper takes a more stylized approach in the sense that income and inflation are determined by exogenous processes, but instead focuses more on the empirical consistency including the Phillips curve. ${ }^{4}$ In terms of the methodology, this paper uses a model with buffer-stock savings pioneered by Deaton (1991) and Carroll (1992). In the finance literature, Heaton and Lucas $(1996,1997)$ use this type of model to investigate equity premiums and portfolio choices, and Aoki et al. (2014) incorporate inflation to investigate the money demand. As far as I know, however, this is the first paper to apply this framework to the term structure of interest rates. Finally, the present paper is also related to the macro econometrics literature using an unobserved component model to decompose the cyclical and trend component. ${ }^{5}$ The most closely related works in this literature are Kuttner (1994) and Domenech and Gomez (2006). As in the present paper, those two papers use the unobserved component model to decompose the trend and cycle and estimate dynamics of inflation and real economic activities including the Phillips curve.

The rest of paper proceeds as follows. Section 2 describes the model to analyze the equilibrium yield curve, and Section 3 estimates the income and inflation process and provides quantitative analyses. Concluding remarks are given in Section 4.

\section{Model}

The model is an endowment economy with optimal savings as a buffer stock. In the model, a representative consumer optimizes its consumption path under an exogenous income and inflation

\footnotetext{
${ }^{4}$ Also, the stylized approach makes it possible to analyze the yield curve in the low-for-long economy. A new Keynesian model faces inflation indeterminacy when interest rates hit the ZLB so often.

${ }^{5}$ The seminal papers in the early literature on this issue are Harvey (1985) and Clark (1987).
} 
process as well as nominal interest rates set by a monetary policy rule. Then, the equilibrium yield curve is defined to be consistent with the first-order conditions for consumers' intertemporal optimization.

\section{A. Budget Constraint}

In every period, the consumer obtains real income, $Y_{t}$, as an endowment, and allocates it for consumption, $C_{t}$, and savings as a form of one-period nominal bonds, $B_{t}$, or $n$-period nominal bonds, $B_{n, t}$. Hence, the budget constraint for the consumer is formulated as

$$
P_{t} C_{t}+\frac{B_{t}}{R_{t}}+\sum_{n>1} Q_{n, t} B_{n, t}+\Phi\left(\frac{B_{t}}{R_{t}}\right)=P_{t} Y_{t}+B_{t-1}+\sum_{n>1} Q_{n-1, t} B_{n, t-1}
$$

where $P_{t}$ is a price level, $R_{t}$ is a nominal interest rate, and $Q_{n, t}$ is a $n$-period bond price in period $t$. Note that, by definition, $Q_{1, t}=1 / R_{t}$ and $Q_{0, t}=1$. Here, a tiny cost for bond holdings, $\Phi(\cdot)$, satisfying

$$
\Phi^{\prime}\left(\frac{B_{t}}{R_{t}}\right)>0 \text { and } \Phi^{\prime \prime}\left(\frac{B_{t}}{R_{t}}\right)>0
$$

is assumed to exist in order to avoid the divergence of bond holdings. ${ }^{6}$ Intuitively, the cost of bond holdings represents a risk premium associated with too much issuance of government bonds, including fiscal risks.

The consumer's real income, $Y_{t}$, is assumed to consist of the non-stationary component, $y_{t}^{*}$, and the stationary component, $y_{t}$,

$$
\log \left(Y_{t}\right)=\log \left(y_{t}^{*}\right)+\log \left(y_{t}\right)
$$

and the growth rate of the non-stationary component, $g_{t} \equiv y_{t}^{*} / y_{t-1}^{*}$, and the stationary component, $y_{t}$, follow a stationary process with $\mathbb{E}\left(g_{t}\right)=g^{*}$ and $\mathbb{E}\left(\log \left(y_{t}\right)\right)=0$. Hence, the growth rate of household's income fluctuates around the constant level of potential growth rate, $g^{*}$, and the cyclical part, $y_{t}$, fluctuates around the non-stationary part of income, $y_{t}^{*}$, over the business cycle. Hereafter, $y_{t}$ is called "income gap" because it is constructed by an analogous way to construct output gap, and $y_{t}^{*}$ is called "long-run income" according to the literature of the long-run shock pioneered by Bansal and Yaron (2004). Similarly, the gross inflation rate is defined as $\Pi_{t} \equiv$

\footnotetext{
${ }^{6}$ This type of "risk premium" for bond holdings is common in a model with exogenous interest rates, typically a small open economy model. See Schmitt-Grohe and Uribe (2003) for more discussion on how to avoid the divergent path in a small open economy model.
} 
$P_{t} / P_{t-1}$, and is assumed to consist of a non-stationary component, $\pi_{t}^{*}$, and a stationary component, $\pi_{t}$, as in Cogley and Sbordone (2008),

$$
\log \left(\Pi_{t}\right)=\log \left(\pi_{t}^{*}\right)+\log \left(\pi_{t}\right)
$$

where $\xi_{t} \equiv \pi_{t}^{*} / \pi_{t-1}^{*}$ and $\pi_{t}$ follow an exogenous stationary process. Hereafter, $\pi^{*}{ }_{t}$ and $\pi_{t}$ are called "trend inflation" and "inflation gap," respectively.

\section{B. Monetary Policy}

As in a standard monetary model, the central bank sets the nominal interest rate, $R_{t}$, by a policy rule responding to inflation. More specifically, the central bank is assumed to set the nominal interest rate at the neutral interest rate (the trend inflation plus the potential growth), $R_{t}^{*} \equiv \pi_{t}^{*} g^{*}$, when inflation is equal to trend inflation (i.e., the inflation gap is equal to zero), and increase (decrease) the nominal interest rate in response to the positive (negative) inflation gap, $\pi_{t} \equiv \Pi_{t} / \pi_{t}^{*}$. That is, the central bank sets the nominal interest rate following a policy rule,

$$
R_{t}=R_{t-1}^{\phi_{r}}\left[R_{t}^{*}\left(\frac{\Pi_{t}}{\pi_{t}^{*}}\right)^{\phi_{\pi}}\right]^{1-\phi_{r}} .
$$

Note that the nominal interest rate is assumed to depend on the last period's interest rate, $R_{t-1}$, as in the previous literature, suggesting that the central bank tends to smoothly make changes in monetary policy. Here, $\phi_{r}$ and $\phi_{\pi}$ are parameters representing the degree of interest rate smoothing and responses to inflation gaps.

\section{Household's Optimization and Equilibrium Yield Curve}

The household chooses their optimal consumption path so as to maximize their discounted lifetime utility. More specifically, the household maximizes the following value function based on the Epstein-Zin-Weil preference,

$$
V_{t}=\left\{C_{t}^{1-\sigma}+\beta \mathbb{E}_{t}\left[V_{t+1}^{1-\alpha}\right]^{\frac{1-\sigma}{1-\alpha}}\right\}^{\frac{1}{1-\sigma}}
$$

subject to the budget constraint (1), the exogenous process of real income and inflation, $Y_{t}$ and $\Pi_{t}$, and the nominal interest rate set by the monetary policy rule (4). Here, $\sigma$ and $\alpha$ are parameters for the inverse of IES and the CRRA coefficient, respectively. 
The equilibrium is characterized by the Euler equation with respect to one-period nominal bond holdings, $B_{t}$,

$$
R_{t} E_{t}\left[M_{t, t+1}\right]=1
$$

and the Euler equations with respect to $n$-period nominal bond holdings, $B_{n, t}$,

$$
E_{t}\left[Q_{n-1, t+1} M_{t, t+1}\right]=Q_{n, t}, \forall n>1 .
$$

Here, $M_{t, t+1}$ is the nominal stochastic discount factor (SDF) from period $t$ to $t+1$,

$$
M_{t, t+1}=\frac{\beta}{\Pi_{t+1}}\left(\frac{C_{t+1}}{C_{t}}\right)^{-\sigma}\left[\frac{V_{t+1}}{\mathbb{E}_{t}\left(V_{t+1}^{1-\alpha}\right)^{\frac{1}{1-\alpha}}}\right]^{\sigma-\alpha} .
$$

The equilibrium nominal yield curve is formulated by $n$-period bond prices, $Q_{n, t}$,

$$
R_{n, t} \equiv Q_{n, t}^{-\frac{1}{n}}
$$

and the nominal term premium for the $n$-period bond, $\psi_{n, t}^{N}$, is defined as,

$$
\psi_{n, t}^{N} \equiv R_{n, t}-\hat{R}_{n, t}
$$

where $\hat{R}_{n, t}$ is a $n$-period bond return for risk-neutral agents. As in the previous literature, the $n$-period bond prices and returns for risk-neutral agents, $\hat{Q}_{n, t}$ and $\hat{R}_{n, t}$, can be defined as,

$$
\frac{1}{R_{t}} \mathbb{E}_{t}\left[\hat{Q}_{n-1, t+1}\right]=\hat{Q}_{n, t} \text { and } \hat{R}_{n, t}=\left(\frac{1}{\hat{Q}_{n, t}}\right)^{\frac{1}{n}}, \forall n>1
$$

because risk-neutral agents are not concerned about the covariance risk.

In a similar vein, the real interest rate, $r_{t}$, and the $n$-period real bond price, $q_{n, t}$, are determined by the asset pricing formula,

$$
r_{t} E_{t}\left[m_{t, t+1}\right]=1
$$

and

$$
E_{t}\left[q_{n-1, t+1} m_{t, t+1}\right]=q_{n, t}, \forall n>1
$$

where $m_{t, t+1}$ is the real SDF from period $t$ to $t+1{ }^{7}$

$$
m_{t, t+1}=\beta\left(\frac{C_{t+1}}{C_{t}}\right)^{-\sigma}\left[\frac{V_{t+1}}{\mathbb{E}_{t}\left(V_{t+1}^{1-\alpha}\right)^{\frac{1}{1-\alpha}}}\right]^{\sigma-\alpha} .
$$

\footnotetext{
${ }^{7}$ The real interest rate and long-term real bond prices are formulated using the real SDF and standard asset pricing formula based on the Euler equations. Those Euler equations, however, can be derived by assuming that real bonds are available for the household and the household optimally chooses the amount of real bond holdings.
} 
Then, the equilibrium real yield curve is formulated by $n$-period bond prices, $q_{n, t}$,

$$
r_{n, t} \equiv q_{n, t}^{-\frac{1}{n}},
$$

and the real term premium for the $n$-period bond, $\psi_{n, t}^{R}$, is defined as,

$$
\psi_{n, t}^{R} \equiv r_{n, t}-\hat{r}_{n, t}
$$

where $\hat{r}_{n, t}$ is a $n$-period real bond return for risk-neutral agents. The $n$-period real bond prices and returns for risk-neutral agents, $\hat{q}_{n, t}$ and $\hat{r}_{n, t}$, are defined as,

$$
\frac{1}{r_{t}} \mathbb{E}_{t}\left[\hat{q}_{n-1, t+1}\right]=\hat{q}_{n, t} \text { and } \hat{r}_{n, t}=\left(\frac{1}{\hat{q}_{n, t}}\right)^{\frac{1}{n}}, \forall n>1
$$

as in the case of nominal bond prices. Finally, the inflation term premium, $\psi_{n, t}^{I}$, is defined as a gap between nominal and real term premiums,

$$
\psi_{n, t}^{I} \equiv \psi_{n, t}^{N}-\psi_{n, t}^{R}
$$

Note that while the all term premiums are zero for $n=1$ (i.e., $\psi_{1, t}^{I}=\psi_{1, t}^{N}=\psi_{1, t}^{R}=0$ ) by definition, it does not mean there is no inflation risk premium for the one-period nominal bond. That is, unless $\operatorname{Cov}\left(\Pi_{t+1}, M_{t, t+1}\right)=0$ is satisfied, $r_{t}=R_{t} / \mathbb{E}_{t}\left[\Pi_{t+1}\right]$ is not satisfied and so the breakeven inflation is not equal to inflation expectations due to the inflation risk premium in the model. ${ }^{8}$

To make the model quantitatively tractable, it is assumed that the supply of $n$-period bond for $n>1$ is equal to zero in equilibrium without loss of generality, and consequently one-period nominal bonds are the only choice of savings for consumers in equilibrium. Moreover, to make the model stationary, all non-stationary variables should be detrended by by $P_{t}, \pi_{t}^{*}$ and/or $y_{t}^{*}$, and all equations including the budget constraint, the monetary policy rule, and the Euler equations should be reformulated by the detrended variables. See Appendix A for the detrending procedure and all relevant equations after detrending. Then, since the model consists of two endogenous, $\left(B_{t-1}, R_{t-1}\right)$, and four exogenous state variables, $\left(g_{t}, \xi_{t}, y_{t}, \pi_{t}\right)$, it is computationally solvable. In the later section, the model is solved quantitatively under the estimated process of income and inflation, and used for examining whether the equilibrium yield curve in the model can account for the empirical features of yield curve in US and UK and for investigating what the model predicts about the equilibrium yield curve in the low-for-long economy.

\footnotetext{
${ }^{8}$ See Ngo and Gourio (2016) for more discussion on inflation risk premiums and how they change around the ZLB of nominal interest rates.
} 


\section{Quantitative Analysis}

This section conducts a quantitative analysis based on the model described in Section 2. Specifically, the quantitative analysis in this section asks: Can the model quantitatively rationalize the shape of yield curves, particularly positive and sizable term premiums, under the estimated process of income and inflation? What is the role of monetary policy in shaping yield curves? In addition to analyzing the baseline case with the stochastic trend, $g_{t}$, the equilibrium yield curve in a trendstationary model is also examined for comparison purpose, given that analyzing the equilibrium yield curve in the trend-stationary model is much more common in the literature (e.g., Rudebusch and Swanson (2012)).

The outline of the quantitative analysis is as follows: first, the income and inflation process is estimated using US and UK data both in the stochastic trend case and in the trend stationary case. Then, given the income and inflation process calibrated by the estimation result, the consumer's optimal policy functions in the model are quantitatively computed by a recursive method. The equilibrium yield curve in the model is computed by plugging estimated inflation and income sequences into the optimal policy function of consumption. After examining whether the equilibrium yield curves can account for the shape of yield curves in data, a counterfactual policy experiment is conducted to examine what the model predict about the slope of yield curves in the economy with permanently low growth and low inflation.

\section{A. Estimation of Income and Inflation Process}

In the model, income and inflation are assumed to consist of a trend and cyclical component as described in (2) and (3). The goal of this subsection is to estimate the parameters for the income and inflation process in US and UK by using a Bayesian method of an unobservable component model, and, in the stochastic trend model, simultaneously decompose the income and inflation process into the trend and cyclical component. The income and inflation process estimated in this subsection will be used for calibrating those in the model to conduct a quantitative analysis in the next subsection.

\section{Econometric Specification and Data}

To estimate the income and inflation process, first, we need to specify the functional form of the income and inflation process. In the trend stationary model, on the one hand, the cyclical part of income and inflation, $y_{t}$ and $\pi_{t}$, are assumed to jointly follow a reduced form VAR(1). That is, the 
vector of an income gap and an inflation gap, $X_{t} \equiv\left[\log \left(y_{t}\right), \log \left(\pi_{t}\right)\right]^{\prime}$ follows a VAR(1):

$$
X_{t+1}=A_{1} X_{t}+\varepsilon_{X, t+1}, \quad \varepsilon_{X, t+1} \sim N\left(0, \Sigma_{X}\right)
$$

where:

$$
A_{1}=\left[\begin{array}{ll}
\rho_{y y} & \rho_{y \pi} \\
\rho_{\pi y} & \rho_{\pi \pi}
\end{array}\right], \Sigma_{X}=\left[\begin{array}{ll}
\sigma_{y y} & \sigma_{y \pi} \\
\sigma_{y \pi} & \sigma_{\pi \pi}
\end{array}\right],
$$

In the trend-stationary model, since the growth rate of long-run income, $g_{t}$, is assumed to be constant at $g^{*}$, the stochastic process of $g_{t}$ does not need to be specified. In the above VAR(1) setting for income and inflation gaps, inflation is assumed to be possibly non-neutral contemporaneously $\left(\sigma_{y \pi} \neq 0\right)$ as well as with lags ( $\rho_{\pi y} \neq 0$ and $\rho_{y \pi} \neq 0$ ). While the inflation non-neutrality is expected to entail the positive association between income and inflation over the business cycle according to the Phillips curve literature, those parameters will be estimated by data with improper priors. Finally, growth of trend inflation, $\xi_{t} \equiv \pi_{t}^{*} / \pi_{t-1}^{*}$, is assumed to follow $\operatorname{AR(1):~}$

$$
\log \left(\xi_{t}\right)=\rho_{\xi} \log \left(\xi_{t-1}\right)+\varepsilon_{\xi, t} \text { where } \varepsilon_{\xi, t} \sim \operatorname{iidN}\left(0, \sigma_{\xi}\right)
$$

When setting the prior distribution for estimation, a very persistent process with very small variance is assumed for the trend inflation process to capture its slow-moving feature.

In the stochastic trend model, on the other hand, since growth of the non-stationary income, $g_{t} \equiv y_{t}^{*} / y_{t-1}^{*}$, is also a stochastic variable in addition to income and inflation gaps, the functional form for the process of $g_{t}$ should be specified, too. Here, it is assumed that $g_{t}$ follows an AR(1) process and that the shock to $g_{t}$ is possibly correlated with the shock to inflation, which can entail another inflation non-neutrality in the stochastic trend model, in addition to the one induced by the correlation between income gaps and inflation gaps. The assumption of AR(1) process for $g_{t}$ is a little bit non-standard in the literature of the unobserved component model in sense that most models in the previous literature assume that $g_{t}$ is a white noise (i.e., $y_{t}^{*}$ follows a random walk). However, given that the long-run shock literature pioneered by Bansal and Yaron (2004) emphasizes the importance of a persistent and non-stationary shock for asset pricing, I assume that the income process possibly contains a non-stationary component more persistent than a random walk process here. ${ }^{9}$ Given this specification for $g_{t}$ in the stochastic trend model, the vector of an income

\footnotetext{
${ }^{9}$ Note that the general AR(1) process for $g_{t}$ here includes a random walk process as a special case, and so a random walk process can be chosen as a result of estimation. Furthermore, assuming a random walk process for the nonstationary component of income has a risk to overestimate the role of a non-stationary component. See Quah (1992) for more theoretical discussion on the trend and cycle decomposition assuming that the non-stationary component follows a general ARIMA process.
} 
gap, an inflation gap, and growth of non-stationary income, $X_{t} \equiv\left[\log \left(y_{t}\right), \log \left(\pi_{t}\right), \log \left(g_{t}\right)\right]^{\prime}$ jointly follows a $\operatorname{VAR}(1)$ :

$$
X_{t+1}=A_{0}+A_{1} X_{t}+\varepsilon_{X, t+1}, \quad \varepsilon_{X, t+1} \sim N\left(0, \Sigma_{X}\right)
$$

where:

$$
A_{0}=\left[\begin{array}{c}
0 \\
0 \\
\left(1-\rho_{g}\right) g^{*}
\end{array}\right], A_{1}=\left[\begin{array}{ccc}
\rho_{y y} & \rho_{y \pi} & 0 \\
\rho_{\pi y} & \rho_{\pi \pi} & 0 \\
0 & 0 & \rho_{g}
\end{array}\right], \Sigma_{X}=\left[\begin{array}{ccc}
\sigma_{y y} & \sigma_{y \pi} & 0 \\
\sigma_{y \pi} & \sigma_{\pi \pi} & \sigma_{g \pi} \\
0 & \sigma_{g \pi} & \sigma_{g g}
\end{array}\right],
$$

where the average of income growth rate is equal to $g^{*}$, which can be interpreted as a long-term potential growth rate in the economy. ${ }^{10}$ Finally, growth of trend inflation, $\xi_{t}$, is assumed to follow a $\mathrm{AR}(1)$ process as in the trend stationary model in (5).

Then, to estimate the parameters in the above income and inflation process by a Bayesian method, we set the prior distributions as follows. First, for identifying between trend and cycle in inflation, it is assumed that: (1) the prior distribution for the $\mathrm{AR}(1)$ parameter of trend inflation is centered around a very high persistence (Beta[0.95, 0.03]), and (2) volatility of trend inflation is assumed to be very small and equal to 1.0 percent of the volatility of inflation gap, i.e., $\sigma_{\xi} / \sigma_{\pi}=0.01$. That is, the trend inflation is identified by defining it as a very persistent and less volatile component of inflation by assumption. Second, in the stochastic trend model, a tight prior distribution (Beta[0.80, 0.05]) is assigned for the $\operatorname{AR}(1)$ parameter of the income gap, $\rho_{y}$, for identifying between trend and cycle in the income process. That is, the income process in the stochastic trend model is decomposed into a trend and cyclical component by assuming that the cyclical part of income is a stationary process near the business cycle frequency. In the trend stationary model, on the other hand, it is not necessary to decompose the income process into a trend and cycle component because, as stated below, the observable variable for $y_{t}$ is the income process detrended by the HP filter and so expected to capture the business cycle component by construction. Hence, in the trend stationary model, a more standard and flatter prior distribution is assumed for $\rho_{y}$. Third, an improper and flat prior distribution, Uniform [-1,1], is assigned to $\rho_{y \pi}, \rho_{\pi y}, \sigma_{\pi g}$, and $\sigma_{\pi y}$ for the stochastic trend model and $\rho_{y \pi}, \rho_{\pi y}$, and $\sigma_{\pi y}$ for the trend stationary model, implying that those parameters are estimated purely by data without any restrictive prior assumptions. Since the co-movement between income and inflation is strongly influenced by those parameters,

\footnotetext{
${ }^{10}$ Here, the correlation between the shocks to a stationary and a non-stationary component of income, the leftbottom and the right-upper component of the covariance matrix, is assumed to be zero. While this assumption is a bit restrictive, it is necessary to identify and decompose the trend and cycle component of income. See Harvey (1985) for more details on this assumption.
} 
the co-movement implied by the estimated inflation and income sequences can be also interpreted as estimated purely by data without any prior restrictions. Finally, other prior distributions are set to conventional ones.

With the above prior distributions, I estimate the eleven parameters

$$
\left(\rho_{g}, \rho_{y y}, \rho_{\pi \pi}, \rho_{y \pi}, \rho_{\pi y}, \rho_{\xi}, \sigma_{g g}, \sigma_{y y}, \sigma_{\pi \pi}, \sigma_{y \pi}, \sigma_{g \pi}\right)
$$

for the stochastic trend model and the eight parameters

$$
\left(\rho_{y y}, \rho_{\pi \pi}, \rho_{y \pi}, \rho_{\pi y}, \rho_{\xi}, \sigma_{y y}, \sigma_{\pi \pi}, \sigma_{y \pi}\right)
$$

for the trend stationary model by a Bayesian method using US and UK data. For inflation, "PCE deflator (chain price index)" is used for US and "Long Term Price Indicator of Consumer Goods and Services" is used for UK. Also, for the real income data, "Personal Income" is used for US and "Real Household Disposable Income" is used for UK. The sample periods are 1959Q2 - 2017Q4 for US and 1959Q2 - 2017Q4 for UK. In the stochastic trend model, the observation equations in the state space representation are:

$$
\begin{aligned}
\Delta \log \left(\Pi_{t}^{\text {Data }}\right) & =\xi_{t}+\pi_{t}-\pi_{t-1} \\
\Delta \log \left(Y_{t}^{\text {Data }}\right) & =g_{t}+y_{t}-y_{t-1}
\end{aligned}
$$

where $\Delta\left(Y_{t}\right)$ is real income growth and $\Delta \log \left(\Pi_{t}\right)$ is changes in inflation in each country. To estimate the income and inflation process in the trend stationary model, on the other hand, first, the data for income gap, $y_{t}$, is constructed by extracting the business cycle component of income using the HP filter, as in a standard business cycle analysis. Then, the observation equations in the state space representation are formulated as:

$$
\begin{aligned}
\Delta \log \left(\Pi_{t}^{\text {Data }}\right) & =\xi_{t}+\pi_{t}-\pi_{t-1} \\
\log \left(Y_{t}^{\text {Data }}\right) & =y_{t}
\end{aligned}
$$

where $\log \left(Y_{t}^{\text {Data }}\right)$ here is a business cycle component of income extracted by the HP filter.

\section{Estimation Results}

The first two columns of Table 1 show the posterior mean and 90 percent confidence intervals for the stochastic trend case, along with the prior distributions. There are some noteworthy features in the estimation results for the stochastic trend case. First, the estimation result points to the 
existence of the Phillips curve, i.e., the positive association between income gap and inflation gap over the business cycle. In both US and UK, the lagged income gap (inflation gap) is positively correlated with inflation gap (income gap) ( $\rho_{y \pi}>0$ and $\rho_{\pi y}>0$ ), and the shock to income gap is also positively correlated with the shock to inflation $\left(\sigma_{\pi y}>0\right){ }^{11}$ Figure 1 shows the scatter plots of estimated inflation gap and income gap in the stochastic trend case, pointing to a strongly positive correlation between inflation and income gap in US and UK. Second, the estimation result shows that inflation is negatively correlated with long-run income growth. The table shows that the shock to the growth of long-run income is negatively correlated with the shock to inflation gaps $\left(\sigma_{\pi g}<0\right)$, and due to the negatively correlated shocks, inflation gaps and growth of longrun income are strongly and negatively correlated, as shown by the scatter plot in Figure 2. In sum, the estimation result for the stochastic trend case implies that inflation is positively correlated with income gap but negatively correlated with growth of long-run income. It is worth noting that improper and flat prior distributions, Uniform [-1,1], are applied to $\rho_{y \pi}, \rho_{\pi y}, \sigma_{\pi g}$, and $\sigma_{\pi y}$, implying that the estimated co-movement between inflation and income is interpreted as the one estimated purely by data without any prior restrictions.

These estimation results for the stochastic trend case are in line with the previous empirical literature on macroeconomic fluctuations. First, the positive association between income gap and inflation over the business cycle is consistent with the Phillips curve literature. That is, given that income gap can be interpreted as one of variables to represent real economic activity over the business cycle, the above estimation result is consistent with the positive correlation between real economic activity and inflation over the business cycle, which has been long argued in the literature (e.g., Kuttner (1994) and Stock and Watson (1999)). Second, the negative correlation between inflation and growth of non-stationary income is consistent with the past VAR literature on the identification of supply and demand shock. Blanchard and Quah (1989) identify the supply and demand shock by assuming that the supply shock has a permanent effect on output while the demand shock does not, and shows that the supply and demand shock has a positive and negative effect on unemployment rates, respectively. Given the negative correlation between inflation and unemployment rates as argued in the Phillips curve literature, Blanchard and Quah (1989)'s result implies that inflation is positively correlated with a stationary part of output but negatively corre-

\footnotetext{
${ }^{11}$ The estimation result for $\rho_{y \pi}>0$ seems a bit strange at the first glance because it seems to imply that lagged high inflation causes high income. This interpretation is, however, not appropriate because the VAR in this paper is just a reduced form VAR rather than a structural VAR. Hence, we would need an identification assumption to know the marginal effect of exogenous shift of lagged inflation on income.
} 
lated with growth of non-stationary part of output, which is consistent with the estimated income and inflation processes in Figure 1 and 2.

The last two columns of Table 1 show the posterior mean and 90 percent confidence intervals for the trend stationary case, along with the prior distributions. There are some key differences from the stochastic trend case. First, while the lagged income gap has positive effects on inflation $\left(\rho_{p y}>0\right)$, the lagged inflation has negative effects on income gap $\left(\rho_{y p}<0\right)$. Thus, it can be interpreted that the first equation in the VAR(1) represents a demand curve while the second equation in the VAR(1) represents a supply curve (or, the Phillips curve). Second, the correlation between the shocks to income and inflation gap is estimated as negative $\left(\sigma_{\pi y}<0\right)$. While those negatively correlated shocks are consistent with the model setting by Rudebusch and Swanson (2012) where the economy is mainly driven by supply shocks, it appears to be inconsistent with the Phillips curve literature which argues that correlation between inflation and real economic activity over the business cycle is positive. However, even with the negative contemporaneous correlation between the shocks, the scatter plot for inflation gaps and lagged income gaps $\left(\pi_{t}\right.$ and $\left.y_{t-1}\right)$ in Figure 3 points to a positive association between those two variables over the business cycle, suggesting that a kind of the Phillips curve exists also in the trend stationary model. In the next subsection, we calibrate the income and inflation process in the trend stationary model using this estimation result and compare the equilibrium yield curves in the trend stationary model with those in the stochastic trend model.

\section{B. Simulation Exercise for Term Structure of Interest Rates}

In the simulation exercise for term structure of interest rates, first, the policy functions under the estimated income and inflation process are computed by the time iteration method with discretized grids proposed in Coleman (1991). Then, the equilibrium yield curve in the model is computed by plugging the sequence of $g_{t}, y_{t}, \xi_{t}$ and $\pi_{t}$ estimated in the previous subsection into the policy functions for each country.

\section{Calibration}

First, the process of income and inflation by country is approximated by a first-order Markov chain with discretized grids. More specifically, the VAR for income gaps, inflation gaps, and growth of long-run income, $X_{t} \equiv\left[\log \left(y_{t}\right), \log \left(\pi_{t}\right), \log \left(g_{t}\right)\right]^{\prime}$, is approximated as follows. First, the state space for $\log \left(y_{t}\right), \log \left(\pi_{t}\right)$, and $\log \left(g_{t}\right)$ is discretized by grids of $G_{y} \in \mathbb{R}^{N_{y}}, G_{\pi} \in \mathbb{R}^{N_{\pi}}$, 
and $G_{g} \in \mathbb{R}^{N_{g}}$ where $N_{y}, N_{\pi}$ and $N_{g}$ are the number of grids for income gap, inflation gap, and long-run income growth. Then, the VAR(1) is approximated by a first-order Markov chain over $G_{X} \in \mathbb{R}^{N_{y}} \times \mathbb{R}^{N_{\pi}} \times \mathbb{R}^{N_{g}}$ by the method proposed in Terry and Knotek II (2011). ${ }^{12}$ Note that the VAR(1) process in the trend stationary model is also approximated by a first-order Markov chain in the same manner just by assuming that there is only one grid for $g_{t}=g^{*}$. The AR(1) process for growth of trend inflation, $\xi_{t}$, is also approximated by a first-order Markov chain by the Tauchen's method.

Second, other parameter values are calibrated to standard values. For preference parameters, the discount rate $\beta$ and the inverse of IES, $\sigma$, are set to 0.9985 and 2.0, which are standard values in the literature. The steady state value for bond holdings, $b^{*}$, is set to 4.8 based on the average asset-income ratio in the U.S., but it barely influences the quantitative results. For the cost of bond holdings, first, its functional form is assumed to be quadratic,

$$
\Phi\left(\frac{b_{t}}{\tilde{R}_{t}}\right) \equiv \frac{\phi_{b}}{2}\left(\frac{b_{t}}{\tilde{R}_{t}}-\frac{b^{*}}{R^{*}}\right)^{2} \tilde{R}_{t},
$$

and set the parameter, $\phi_{b}$, to an arbitrary small number, 0.001 , just for avoiding divergence of bond holdings. Note that the value of the bond holding cost barely affects the results, too. For the parameters of the monetary policy rule, the interest rate smoothing, $\phi_{r}$, is set to 0.8 for both countries, and the degree of response to inflation, $\phi_{\pi}$, is set to 2.0 for US and 1.0 for UK, based on the previous DSGE literature including Negro et al. (2013) for US and DiCecio and Nelson (2007) for UK. As for the degree of response to inflation, however, the sensitivity analysis will be conducted in the next subsection because it is one of the key parameters in shaping the equilibrium yield curve as shown later. Finally, the CRRA parameter $\alpha$ will be chosen so that the level of average term premiums fits the data as shown in the next section. Table 2 summarizes the calibration values in the baseline case.

\section{Equilibrium Yield Curve and Its Driving Force}

Before discussing the simulation results, I briefly touch on stylized facts about yield curves. Table 3 shows the average shape of yield curve and the volatility of interest rates for the overnight rate, the 5-year rate, and the 10-year rate in US and UK. The table is based on the data for government bonds in each maturity for 1959Q1-2017Q1 for US and 1957Q1-2017Q1 for UK. The values in parentheses for the level of interest rates are the average spreads relative to the short-term interest

\footnotetext{
${ }^{12}$ I thank the authors for kindly sharing the Matlab code.
} 
rates, which are theoretically close to term premiums for 5-year and 10-year bonds, and the values in parentheses for the volatility are the volatility of long-term interest rates relative to the volatility of the short-term interest rates. The table shows two stylized facts shared across US and UK. First, the yield curve is upward sloping on average. For instance, the spread for the 10-year interest rate is $1.07 \%$ and $0.84 \%$ in US and UK, respectively. Since the spread between the long-term interest rate and the short-term interest rate is determined by term premiums on average in the long run, those upward sloping yield curves imply that term premiums are positive and larger for longerterm interest rates in data. ${ }^{13}$ Second, volatility of long-term interest rate is slightly smaller than volatility of short-term interest rates but almost at the same level. As is investigated later, it is theoretically puzzling that the long-term interest rate has almost the same level of volatility. In what follows, I will explore whether the model can account for those stylized facts and what is the economic intuition behind it.

Figure 4 shows the equilibrium yield curves in the stochastic trend model (the baseline model) and the trend stationary model, along with the average level of term spreads in actual data for US and UK. In this simulation, the CRRA coefficient is set to $\alpha=40$ for US and $\alpha=20$ for UK to quantitatively fit the simulation results to data. The main takeaway from the figure is that the baseline model (the bold blue lines) can successfully account for the upward sloping yield curves in both countries under the estimated process of income and inflation. Furthermore, the figure also shows that the equilibrium yield curve in the trend stationary model (the red lines with x-mark) obviously fails to generate sizable term premiums and thus the equilibrium yield curve in the trend stationary model is too flat to fit the data. Hence, while the trend stationary model is more common than the stochastic trend model in the literature, the figure indicates that the equilibrium yield curve in the trend stationary model cannot solve the "bond premium puzzle" if the income and inflation process is calibrated to be consistent with data. ${ }^{14}$

Why can the baseline model generate positive and sizable term premiums and account for the

\footnotetext{
${ }^{13} \mathrm{An}$ implicit assumption here is that there have been no substantial structural breaks in the bond market to permanently change the level of term premiums, and that all policy changes associated with the bond market, including the quantitative easing after the global financial crisis, are cyclical policy changes.

${ }^{14}$ While the value of CRRA coefficient quantitatively influences the slope of yield curve as is well known, note that the qualitative result of positive and sizable term premiums is preserved for a relatively wide range of CRRA coefficients as shown by a robustness check in Appendix B, and that values of CRRA coefficient enough for replicating the empirically comparable size of term premiums are much more modest and realistic than those in previous literature. Moreover, term premiums in the trend stationary model are almost zero for broad values of CRRA coefficient, suggesting that the performance of the stochastic trend model relative to the trend stationary model does not depend on the value of CRRA coefficient.
} 
upward sloping yield curve, even while preserving the Phillips curve as shown in Figure 1? Since the negative correlation between consumption growth and inflation is a necessary condition for obtaining positive term premiums in any consumption-based asset pricing models, this question can be rephrased as: Why can the model replicate the negative correlation between consumption growth and inflation even though income and inflation are positively correlated over the business cycle? Given the estimation result in the previous section, a key to understanding the mechanism behind the equilibrium yield curve is the difference between the cyclical income and the long-run income in their relation to inflation. On the one hand, the stationary part of income (income gap) entails the Phillips curve just because it is positively correlated with inflation gaps over the business cycle, as shown in Figure 1. On the other hand, growth of long-run income is negatively correlated with inflation as shown in Figure 2. Since consumption growth is more influenced by long-run income than income gaps under the permanent income hypothesis, the negative correlation between growth of long-run income and inflation induces the negative correlation between consumption growth and inflation in the model, thus leading to positive and sizable term premiums, while preserving the positive association between income and inflation over the business cycle.

While the mechanism is simple and clear, this result is in quite contrast with the previous literature. For instance, Rudebusch and Swanson (2012) investigate the equilibrium yield curve in a standard DSGE model where all variables are trend stationary and there is no non-stationary longrun shock, and show that the model can account for an upward sloping yield curve under standard calibration values. However, to replicate the negative correlation between consumption growth and inflation in their model, they implicitly assume that the output gap is negatively correlated with inflation over the business cycle by assuming that the economy is mainly driven by productivity shocks, which contradicts the empirical fact regarding the Phillips curve. As shown by the trend stationary model in Table 4, if we calibrate the income and inflation process in the trend stationary model based on the estimation result, it is quite challenging for the model to replicate positive and sizable term premiums, implying the importance of long-run income shocks in resolving the "bond premium puzzle" similarly to resolving the equity premium puzzle in Bansal and Yaron (2004). ${ }^{15}$ However, as emphasized by Rudebusch and Swanson (2012), incorporating a long-run income shock into a standard DSGE model is tricky because a positive long-run income shock usually leads to a positive rather than negative response of inflation in DSGE models, thus making it difficult for them to replicate the negative association between long-run income growth and

\footnotetext{
${ }^{15}$ See also Bansal and Shaliastovich (2013) for the relationship between long-run risks to exogenous consumption growth and the bond premium puzzle.
} 
inflation shown in Figure 2. Replicating the relationship of stationary and non-stationary income with inflation by using a micro-founded DSGE model is, of course, an interesting and critical issue, but I focus on the asset pricing implications by taking the relationship as given in this paper and leave the issue for future research.

\section{Monetary Policy and Equilibrium Yield Curve}

Table 4 shows real term premiums in the baseline model along with nominal term premiums. The table indicates that a substantial part of nominal term premiums is accounted for by real term premiums particularly in US, and that term premiums associated with inflation risk premiums do not play a dominant role for explaining the upward sloping yield curve. ${ }^{16}$ This result of decomposition is in contrast with the previous theoretical finance literature, which argues that inflation risk premiums rather than real term premiums are a dominant part of nominal term premiums (e.g., Piazzesi and Schneider (2007)), but it is consistent with the empirical finance literature on term premiums. For instance, Abrahams et al. (2016) decompose nominal term premiums in US by estimating the affine term structure model and show that real term premiums are much larger than inflation term premiums.

The response of monetary policy to inflation plays a key role for generating the positive and sizable real term premiums. To understand why, let us think about the 2-period real bond price, $q_{2, t}$. By the Euler equation with respect to real bonds in each maturity, the 2-period real bond price is decomposed as,

$$
\begin{aligned}
q_{2, t} & =\mathbb{E}_{t}\left(q_{1, t+1} m_{t, t+1}\right) \\
& =\mathbb{E}_{t}\left(q_{1, t+1}\right) / r_{t}+\operatorname{cov}\left(1 / r_{t+1}, m_{t, t+1}\right)
\end{aligned}
$$

where $m_{t}$ is the real SDF and $r_{t}$ is a real interest rate in period $t$. This equation implies that real term premiums are positive if and only if $\operatorname{cov}\left(1 / r_{t+1}, m_{t, t+1}\right)<0$. In the model, real interest rate increases in the face of inflation hike because the central bank is assumed to aggressively increase nominal interest rates in response to inflation. Furthermore, the real SDF, $m_{t}$, also increases in response to inflation because consumption growth and inflation are negatively correlated in the model. Taken together those two observations, the real interest rate and the real SDF are positively correlated, thus leading to $\operatorname{cov}\left(1 / r_{t+1}, m_{t, t+1}\right)<0$ and positive real term premiums. Intuitively, if

\footnotetext{
${ }^{16}$ This result does not mean that there are little inflation risk premiums. Inflation risk premiums are positive and significant in this model, but there is not large difference in inflation risk premiums for the short- and the long-term interest rates, suggesting that term premiums associated with inflation risk premiums are not large.
} 
the real interest rate increases in response to inflation, the real bond is not a good hedge against a decline in consumption caused by inflationary shocks, thus leading to positive real term premiums.

The significant effect of monetary policy behavior on term premiums is confirmed by comparative statics with respect to the degree of monetary policy response to inflation, $\phi_{\pi}$. Figure 5 shows that the equilibrium yield curves with different degrees of monetary policy responses to inflation $\left(\phi_{\pi}=1.0,2.0\right.$ and 3.0). The figure indicates that the more aggressively the central bank responds to inflation, the steeper the equilibrium yield curve becomes. The economic intuition behind this result is simple: The more aggressively the central bank responds to inflation, the more negatively nominal (and real) bond prices are correlated with inflation, thus making nominal (and real) bonds riskier assets due to the negative correlation between consumption growth and inflation.

This result of comparative statics, therefore, suggests that differences in the term structure of nominal interest rates across countries are perhaps explained by differences in the monetary policy rule. In the baseline calibration in this paper, the degree of monetary policy response is set to $\phi_{\pi}=2.0$ in US while it is set to $\phi_{\pi}=1.0$ in UK. As explained in the calibration part, this calibration value of monetary policy response to inflation in each country is based on the previous empirical macroeconomic literature, but the smaller monetary policy response to inflation in UK is also justified by volatility of nominal interest rates relative to volatility of inflation. ${ }^{17}$ Table 5 shows the relative volatility of interest rates to inflation in data as well as in the model with $\phi_{\pi}=1.0,2.0$ and 3.0, respectively. The table indicates that while the ratio of interest rate volatility to inflation volatility is much larger than one and close to the case of $\phi_{\pi}=2.0$ in US, it is less than one and close to the case of $\phi_{\pi}=1.0$ in $\mathrm{UK}$, which is consistent with the baseline calibration in this paper. Hence, the results of comparative statics in Figure 5 imply that such a small response of monetary policy to inflation in UK is a key to replicating the moderate level of term premiums in the model, particularly the moderate share of real term premiums as shown in Table 4, even in the face of the very large volatility of inflation in UK.

\footnotetext{
${ }^{17}$ The very low inflation responsiveness of UK monetary policy was probably caused by the fact that the monetary policy in the UK was often Treasury-led and subject to political cycles during 1959-1996. Hence, since the Bank of England independence in 1997 and inflation targeting, the parameters of monetary policy response might possibly change and influence the level of term premiums in UK. While the sample since 1997 is too short to discuss the longterm level of term premiums, the effect of such structural breaks in the monetary policy behavior is an interesting topic for future research.
} 


\section{Term Structure of Interest Rate Volatility}

This subsection examines the term structure of interest rate volatility in order to further verify the validity of the model. The previous subsection shows that the model can successfully account for the level of the long-term interest rate under the observed income and inflation process, but it does not necessarily mean that it can also account for the volatility of long-term interest rate relative to that of short-term interest rate (i.e., the term structure of interest rate volatility). Table 3 shows that volatility of 5-year and 10-year interest rates in US and UK is slightly lower than short-term interest rates. From a theoretical perspective, this slightly lower volatility for long term interest rates is puzzling: Theoretical models predict much lower volatility for long term interest rates than what we observe in data. The economic intuition for "the excess volatility of long term interest rates" in data is simple. Long term interest rates are basically an average of current and expected future short-term interest rates plus term premiums. Hence, if short term interest rates follow a mean reverting stationary process and term premiums do not fluctuate a lot, long term interest rates do not significantly respond to fluctuations in short term interest rates and thus have much smaller volatility than the short-term interest rates do.

Figure 6 shows the relative volatility of long term interest rates in data (the black lines with circles) and in the model (the bold blue lines). The figure indicates that while the relative volatility for long term interest rates is still a little bit lower than data, the model can successfully replicate a relatively large volatility for long term interest rates. A key to understanding this result is the time-varying trend inflation, $\pi_{t}^{*}$. To see the marginal effects of time-varying trend inflation on the relative volatility of long term interest rates, Figure 6 also shows the relative volatility of long term interest rates for the case of fixed trend inflation (the dashed blue lines). The figure indicates that if the trend inflation is fixed at a constant value, the relative volatility of long term interest rates would be much smaller as in a standard model, suggesting that the time varying trend inflation is a main driver for the volatility of long term interest rates. ${ }^{18}$ The reason why the time varying trend inflation boosts the volatility of long term interest rates is as follows: Both short- and long-term interest rates are cointegrated with trend inflation, but since trend inflation follows very persistent non-stationary process, trend inflation influences the long-term interest rates more than short-term interest rates by changing the long-term inflation expectations, thus increasing the volatility of long term interest rates relative to the volatility of short term interest rates.

\footnotetext{
${ }^{18}$ Interestingly, as shown in the robustness check in Appendix B, the level of term premiums is almost the same between the economy with time varying and time invariant trend inflation. See Appendix B for more discussion about the effects of trend inflation on the level of term premiums.
} 
To further support the hypothesis that the slow-moving trend inflation is a key to understanding the relatively large volatility of long term interest rates, Figure 6 also shows the volatility of detrended long-term interest rates relative to the volatility of detrended short-term interest rates (the dashed blue lines with circles). The detrended long- and short-term interest rates are computed by taking the deviation from the HP filter trend for each sequence. The figure indicates that the relative volatility of detrend long term interest rates is much smaller and close to the relative volatility of long-term interest rates in the model without time-varying trend inflation. This result supports the hypothesis because it suggests that the relatively large volatility of long term interest rates in data is mainly driven by non-stationary and slow-moving components such as trend inflation, which captured by the HP filter trend, and that the volatility of long-term interest rates over the business cycle, which is captured by the detrended components, is much smaller than that of short-term interest rates as in a standard model without time varying trend inflation.

The results in Figure 6 have several implications for both the finance and macroeconomics literatures. For the finance literature, the above result implies that the volatility of term premiums may not play a significant role to account for the excess volatility of long term interest rates. This result is consistent with the empirical work by Fuhrer (1996), which shows that the excess volatility for long term interest rates can be accounted for by changes in monetary policy behavior including long-term target inflation. It is also consistent with the recent empirical work by Kurmann and Otrok (2013), which shows that most fluctuations of term spreads are accounted for by the fact that short term interest rates are more volatile than long-term interest rates over the business cycle. This result is basically good news for the finance literature because it implies that the relatively large volatility of long term interest rates can be attributed to trend inflation rather than term premiums, thus making it unnecessary to generate large volatility of term premiums in the model. For the macroeconomic literature, on the other hand, the above result implies that shortand long-term interest rates should be modeled as non-stationary variables cointegrated with each other. The macroeconomic literature usually models interest rates as stationary and mean reverting variables mainly for tractability even though the empirical time series literature usually treats short- and long-term interest rates as non-stationary and cointegrated with each other (See, for instance, Wooldridge (2012)). The above result suggests that macroeconomic models possibly describe such a cointegrated relationship between short- and long-term interest rates by assuming that trend inflation is time-varying and cointegrated with interest rates. 


\section{Macroeconomic Moments for Consumption Growth}

Since the size and sign of term premiums are mostly determined by consumption growth and its relation to inflation as shown in previous sections, it is necessary to check if macroeconomic moments regarding consumption growth do not outrageously deviate from the data. In other words, if those moments are very different from data, they will cast doubt on the results for the equilibrium yield curve because they are possibly generated by counterfactual consumption growth movements and their relation to inflation.

Table 6 shows macroeconomic moments regarding quarterly, yearly, and 2-year consumption growth. The table suggests that the moments are broadly consistent with data, particularly for longer term growth of consumption. While some moments for quarterly data does not fit well to data, it is worth noting that the moments for longer term consumption growth such as yearly growth or 2-year growth are more relevant to term premiums for longer maturities like 5-year bonds and 10-year bonds. Hence, we can conclude that the model can account for both the shape of yield curves and the key macroeconomic moments of consumption growth simultaneously.

\section{Equilibrium Yield Curve in the Low-for-Long Economy}

What does the model predict about the equilibrium yield curve in the economy with permanently low growth and low inflation? Amid the recent low growth and low inflation environment in advanced economies, the low-for-long economy is a real risk for many countries. This subsection tries to address this question by conducting a counterfactual simulation for the low-for-long economy. In the counterfactual simulation, the permanently low growth and low inflation economy is described by setting $\log \left(g^{*}\right)=0$ and $\log \left(\pi_{t}^{*}\right)=0$. Furthermore, the ZLB of nominal interest rate is taken into account to consider the changes of monetary policy behavior around the ZLB. More specifically, the monetary policy rule is changed to,

$$
R_{t}=\max \left\{1.0, R_{t-1}^{\phi_{r}}\left[\pi_{t}^{*} g^{*}\left(\frac{\Pi_{t}}{\pi_{t}^{*}}\right)^{\phi_{\pi}}\right]^{1-\phi_{r}}\right\},
$$

and set $g^{*}=1$ and $\pi_{t}^{*}=1$ for all $t$. Under those assumptions, the equilibrium yield curves are computed by the optimal policy functions for consumption and compared with the baseline case through comparative statics.

The last two rows in Table 4 show the equilibrium nominal and real yield curves in the lowfor-long economy in US and UK. The table indicates that the low-for-long economy would be 
associated with a flatter yield curve in addition to lower level of interest rates: Both in US and UK, the model predicts that the term spreads for 5-year and 10-year bonds would be almost half in the low-for-long economy. Furthermore, the table shows that the decline in real term premiums account for almost all of the decline in nominal term premiums, and that inflation risk premiums are almost unchanged (or slightly higher) in the low-for-long economy.

A key to understanding the result of comparative statics is how the response of real interest rates to inflation changes under the low-for-long economy due to the ZLB of nominal interest rates. Above the ZLB, the return of real bonds, $R_{t} / \pi_{t+1}$, increases (i.e., the price of real bonds decreases) in response to an inflation hike because the monetary policy is assumed to respond to inflation by aggressively increasing nominal interest rates. On the other hand, around the ZLB, the return of real bonds possibly decreases rather than increases in response to an inflation hike because the central bank cannot aggressively respond to inflation due to the ZLB. Hence, the positive correlation between the real SDF and real interest rates would be weakened around the ZLB, thus leading to lower real term premiums in the low-for-long economy. Intuitively, long-term bonds become more like insurance rather than risky assets in the low-for-long economy because inflation decreases consumption growth but at the same time possibly increases real (and nominal) bond prices, thus making long-term bonds a good hedge against a risk for inflation and consumption decline around the ZLB.

The above result implies that a permanently low interest rate environment potentially poses a risk to financial stability. IMF (2017) shows that commercial banks are expected to face lower profitability even without the flattening of yield curves due to, for instance, the decline in net interest margins caused by the ZLB of deposit rates. The results of the counterfactual simulation for the low-for-long economy imply that the low profitability problem in the low-for-long economy might be more severe than expected due to the flattening of yield curves, given that the maturity transformation is a key source of their profits. Since sustainable profits are necessary for commercial banks to build capital buffers, the low profitability problem in the low-for-long environment potentially poses a risk to financial stability. Hence, while the low-for-long economy is still only one of the risks in a limited number of advanced economies, commercial banks and policy makers should keep in mind the risk to financial stability in the low-for-long economy caused by the flatter yield curves. 


\section{Conclusion}

This paper examines the equilibrium yield curve in a model with optimal savings as a buffer stock. The contribution of this paper to the literature is twofold. First, it shows that the shape of yield curve can be rationalized by consumers' optimization under the empirically observed income and inflation dynamics including their positive association over the business cycle, namely the Phillips curve. By estimating the income and inflation process using US and UK data, this paper shows inflation is negatively correlated with long-run income growth but positively correlated with cyclical income fluctuations, thus enabling the model to replicate positive and sizable term premiums on average, along with the Phillips curve over the business cycle. Second, it shows that a monetary policy response to inflation is a key to accounting for the shape of yield curves. Given the importance of monetary policy behavior in shaping yield curves, a counterfactual analysis shows that a permanently low growth and low inflation environment would be associated with flatter yield curves due to changes in monetary policy behavior around the ZLB of nominal interest rates. This result of comparative statics implies that a permanently low interest rate environment potentially poses a risk to financial stability, given that the maturity transformation is a key source of commercial banks' profits.

There are several avenues for the future works following this paper. First, while this paper assumes the exogenous income and inflation processes, a promising but more demanding proposal is to model those variables as endogenous ones in a general equilibrium model and replicate the key features in yield curves at the same time. ${ }^{19}$ This is an important future work, considering the fact that the income and inflation relationship in this paper is estimated by a reduced form regression and such a relationship is subject to change in the future due to some structural breaks. Since this paper shows some necessary conditions for a stationary and non-stationary component of income and their relation to inflation to account for the shape of yield curves, those conditions are good reference for constructing a general equilibrium model. Second, while this paper focuses on the steady-state level of term premiums in the long run, the model proposed in this paper can be potentially applied to the analysis of changes in the shape of yield curves over time. For instance, potential applications include an analysis of the predictability of excess bond returns identified by Cochrane and Piazzesi (2005), as well as an analysis on dynamics of term premiums around the exist from low interest rate policies as investigated in Nakata and Tanaka (2016). Those topics are important ones but left for future research.

\footnotetext{
${ }^{19} \mathrm{Hsu}$ et al. (2016) is one of recent studies in this direction.
} 


\section{References}

Abrahams, M., Adrian, T., Crump, R. K., Moench, E., and Yu, R. (2016). Decomposing Real and Nominal Yield Curves. Journal of Monetary Economics, 84(C):182-200.

Andreasen, M. M. (2012). An Estimated DSGE Model: Explaining Variation in Nominal Term Premia, Real Term Premia, and Inflation Risk Premia. European Economic Review, 56(8):16561674.

Aoki, K., Michaelides, A., and Nikolov, K. (2014). Inflation, Money Demand and Portfolio Choice. Working Paper.

Backus, D. K., Gregory, A. W., and Zin, S. E. (1989). Risk Premiums in the Term Structure : Evidence from Artificial Economies. Journal of Monetary Economics, 24(3):371-399.

Bansal, R. and Shaliastovich, I. (2013). A Long-run Risks Explanation of Predictability Puzzles in Bond and Currency Markets. Review of Financial Studies, 26(1):1-33.

Bansal, R. and Yaron, A. (2004). Risks for the Long Run: A Potential Resolution of Asset Pricing Puzzles. Journal of Finance, 59(4):1481-1509.

Blanchard, O. J. and Quah, D. (1989). The Dynamic Effects of Aggregate Demand and Supply Disturbances. American Economic Review, 79(4):655-673.

Boudoukh, J. (1993). An Equilibrium Model of Nominal Bond Prices with Inflation-Output Correlation and Stochastic Volatility. Journal of Money, Credit and Banking, 25(3):636-665.

Branger, N., Schlag, C., Shaliastovich, I., and Song, D. (2016). Macroeconomic Bond Risks at the Zero Lower Bound. Working paper.

Campbell, J. Y. (1986). Bond and Stock Returns in a Simple Exchange Model. The Quarterly Journal of Economics, 101(4):785-803.

Carroll, C. D. (1992). The Buffer-Stock Theory of Saving: Some Macroeconomic Evidence. Brookings Papers on Economic Activity, 23(2):61-156.

Clark, P. K. (1987). The Cyclical Component of U. S. Economic Activity. The Quarterly Journal of Economics, 102(4):797-814.

Cochrane, J. H. (2017). Macro-Finance. Review of Finance, 21(3):945-985. 
Cochrane, J. H. and Piazzesi, M. (2005). Bond Risk Premia. American Economic Review, 95(1):138-160.

Cogley, T. and Sbordone, A. M. (2008). Trend Inflation, Indexation, and Inflation Persistence in the New Keynesian Phillips Curve. American Economic Review, 98(5):2101-2126.

Coleman, W. (1991). Equilibrium in a Production Economy with an Income Tax. Econometrica, 59(4):1091-1104.

De Paoli, B., Scott, A., and Weeken, O. (2010). Asset Pricing Implications of a New Keynesian Model. Journal of Economic Dynamics and Control, 34(10):2056-2073.

Deaton, A. (1991). Saving and Liquidity Constraints. Econometrica, 59(5):1221-1248.

den Haan, W. J. (1995). The Term Structure of Interest Rates in Real and Monetary Economies. Journal of Economic Dynamics and Control, 19(5-7):909-940.

Dew-Becker, I. (2014). Bond Pricing with a Time-Varying Price of Risk in an Estimated MediumScale Bayesian DSGE Model. Journal of Money, Credit and Banking, 46(5):837-888.

DiCecio, R. and Nelson, E. (2007). An estimated DSGE model for the United Kingdom. Review, (Jul):215-232.

Domenech, R. and Gomez, V. (2006). Estimating Potential Output, Core Inflation, and the NAIRU as Latent Variables. Journal of Business \& Economic Statistics, 24:354-365.

Fuhrer, J. C. (1996). Monetary Policy Shifts and Long-term Interest Rates. Quarterly Journal of Economics, 111(4):1183-1209.

Harvey, A. C. (1985). Trends and Cycles in Macroeconomic Time Series. Journal of Business \& Economic Statistics, 3(3):216-227.

Heaton, J. and Lucas, D. (1997). Market Frictions, Savings Behavior, and Portfolio Choice. Macroeconomic Dynamics, 1(01):76-101.

Heaton, J. and Lucas, D. J. (1996). Evaluating the Effects of Incomplete Markets on Risk Sharing and Asset Pricing. Journal of Political Economy, 104(3):443-487. 
Hsu, A., Li, E. X. N., and Palomino, F. J. (2016). Real and Nominal Equilibrium Yield Curves: Wage Rigidities and Permanent Shocks. Finance and Economics Discussion Series 2016-032, Board of Governors of the Federal Reserve System (U.S.).

IMF (2017). Low Growth, Low Interest Rates, and Financial Intermediation. In Global Financial Stability Report, chapter 2, pages 49-82.

Kurmann, A. and Otrok, C. (2013). News Shocks and the Slope of the Term Structure of Interest Rates. American Economic Review, 103(6):2612-2632.

Kuttner, K. N. (1994). Estimating Potential Output as a Latent Variable. Journal of Business \& Economic Statistics, 12(3):361-368.

Nakata, T. and Tanaka, H. (2016). Equilibrium Yield Curves and the Interest Rate Lower Bound. Finance and Economics Discussion Series 2016-085, Board of Governors of the Federal Reserve System (U.S.).

Negro, M. D., Eusepi, S., Giannoni, M., Sbordone, A. M., Tambalotti, A., Cocci, M., Hasegawa, R. B., and Linder, M. H. (2013). The FRBNY DSGE model. The Federal Reserve Bank of New York, Staff Report No. 647.

Ngo, P. and Gourio, F. (2016). Risk Premia at the ZLB: A Macroeconomic Interpretation. Working Paper.

Piazzesi, M. and Schneider, M. (2007). Equilibrium Yield Curves. In NBER Macroeconomics Annual 2006, Volume 21, NBER Chapters, pages 389-472. National Bureau of Economic Research, Inc.

Quah, D. (1992). The Relative Importance of Permanent and Transitory Components: Identification and Some Theoretical Bounds. Econometrica, 60(1):107-118.

Rudebusch, G. D. and Swanson, E. T. (2008). Examining the Bond Premium Puzzle with a DSGE Model. Journal of Monetary Economics, 55:111-126.

Rudebusch, G. D. and Swanson, E. T. (2012). The Bond Premium in a DSGE Model with LongRun Real and Nominal Risks. American Economic Journal: Macroeconomics, 4(1):105-143.

Schmitt-Grohe, S. and Uribe, M. (2003). Closing Small Open Economy Models. Journal of International Economics, 61(1):163-185. 
Stock, J. H. and Watson, M. W. (1999). Business Cycle Fluctuations in US Macroeconomic Time Series. In Taylor, J. B. and Woodford, M., editors, Handbook of Macroeconomics, Handbook of Macroeconomics, chapter 1, pages 3-64. Elsevier.

Swanson, E. (2016). A Macroeconomic Model of Equities and Real, Nominal, and Defaultable Debt. Working paper.

Terry, S. J. and Knotek II, E. S. (2011). Markov-chain Approximations of Vector Autoregressions: Application of General Multivariate-normal Integration Techniques. Economics Letters, 110(1):4-6.

van Binsbergen, J. H., Fernandez-Villaverde, J., Koijen, R. S., and Rubio-Ramirez, J. (2012). The Term Structure of Interest Rates in a DSGE Model with Recursive Preferences. Journal of Monetary Economics, 59(7):634-648.

Wachter, J. A. (2006). A Consumption-based Model of the Term Structure of Interest Rates. Journal of Financial Economics, 79(2):365-399.

Wooldridge, J. M. (2012). Introductory Econometrics: A Modern Approach. Upper Level Economics Titles. Cengage Learning.

\section{Appendix I: Detrending}

To make the model stationary, all non-stationary variables in the model should be detrended by by $P_{t}, \pi_{t}^{*}$ and/or $y_{t}^{*}$, and all equations including the budget constraint, the monetary policy rule, and the Euler equations should be reformulated by the detrended variables. In what follows, this appendix shows how to detrend the non-stationary variables in the model.

First, the amount of nominal bond holdings is detrended as,

$$
b_{t}=B_{t} /\left(P_{t} y_{t}^{*} \pi_{t}^{*}\right) \text { and } b_{n, t}=B_{n, t} /\left(P_{t} y_{t}^{*} \pi_{t}^{* n}\right) \text {. }
$$

where $b_{t}$ and $b_{n, t}$ are the detrended bond holdings for one-period bonds and $n$-period bonds. Nominal bond holdings are detrended by a price level and long-run income because they are cointegrated with those variables on the balanced growth path as in a standard growth model. In addition, nominal bond holdings should be detrended by the trend inflation, $\pi_{t}^{*}$, because the bond return is cointegrated with it. That is, the detrended nominal interest rate and $n$-period bond prices, $\tilde{R}_{t}$ and $\tilde{Q}_{n, t}$, 
are defined as,

$$
\tilde{R}_{t}=R_{t} / \pi_{t}^{*} \text { and } \tilde{Q}_{n, t}=\pi_{t}^{* n} Q_{n, t} .
$$

Note that the $n$-period bond holdings, $B_{n, t}$, and prices, $Q_{n, t}$, should be detrended by the trend inflation powered by its maturity, $\pi_{t}^{* n}$, because all spot and forward rates up to its maturity should be detrended by the trend inflation. Finally, the detrend consumption, $c_{t}$, is defined by,

$$
c_{t}=C_{t} / y_{t}^{*}
$$

as in a standard neo-classical growth model. Then, the budget constraint is reformulated by those detrended variables as,

$$
c_{t}+\frac{b_{t}}{\tilde{R}_{t}}+\sum_{n>1} \tilde{Q}_{n, t} b_{n, t}+\Phi\left(\frac{b_{t}}{\tilde{R}_{t}}\right)=1+\frac{b_{t-1}}{g_{t} \pi_{t} \xi_{t}}+\frac{\sum_{n>1} \tilde{Q}_{n-1, t} b_{n, t-1}}{g_{t} \pi_{t} \xi_{t}{ }^{n}}
$$

by dividing both sides of the original budget constraint (1) by $P_{t}$ and $y_{t}^{*}$.

As in the budget constraint, the monetary policy rule is also reformulated by using the detrended variables as,

$$
\tilde{R}_{t}=\left(\frac{\tilde{R}_{t-1}}{\xi_{t}}\right)^{\phi_{r}}\left[g^{*} \pi_{t}^{\phi_{\pi}}\right]^{1-\phi_{r}}
$$

by dividing the both sides of the monetary policy rule by trend inflation, $\pi_{t}^{*}$.

Finally, the Euler equations are detrended. The nominal SDF based on detrended variables, $\tilde{M}_{t, t+1}$, is defined by,

$$
\begin{aligned}
\tilde{M}_{t, t+1} & \equiv \pi_{t+1}^{*} M_{t, t+1} \\
& =\frac{\beta}{\Pi_{t+1} / \pi_{t+1}^{*}}\left(\frac{C_{t+1}}{C_{t}}\right)^{-\sigma}\left[\frac{V_{t+1}}{\mathbb{E}_{t}\left(V_{t+1}^{1-\alpha}\right)^{\frac{1}{1-\alpha}}}\right]^{\sigma-\alpha} \\
& =\frac{\beta}{\pi_{t+1}}\left(\frac{c_{t+1}}{c_{t}}\right)^{-\sigma}\left[\frac{v_{t+1}}{\mathbb{E}_{t}\left[\left(v_{t+1} g_{t+1}\right)^{1-\alpha}\right]^{\frac{1}{1-\alpha}}}\right]^{\sigma-\alpha} g_{t+1}^{-\alpha}
\end{aligned}
$$

where $c_{t}=C_{t} / y_{t}^{*}$ and $v_{t}=V_{t} / y_{t}^{*}$. Then, the Euler equations are reformulated by using the new nominal SDF, $\tilde{M}_{t, t+1}$,

$$
\tilde{R}_{t} \mathbb{E}_{t}\left[\frac{\tilde{M}_{t, t+1}}{\xi_{t+1}}\right]=1
$$

and

$$
\mathbb{E}_{t}\left[\frac{\tilde{Q}_{n-1, t+1} \tilde{M}_{t, t+1}}{\xi_{t+1}^{n}}\right]=\tilde{Q}_{n, t}, \forall n>1 .
$$


Finally, the $n$-period bond prices for risk-neutral agents, $\tilde{\hat{Q}}_{n, t}$ are reformulated as,

$$
\frac{1}{\tilde{R}_{t}} \mathbb{E}_{t}\left[\frac{\tilde{\hat{Q}}_{n-1, t+1}}{\xi_{t+1}^{n-1}}\right]=\tilde{\hat{Q}}_{n, t}, \forall n>1
$$

\section{Appendix II: Robustness Check}

This appendix conducts the following four robustness checks to verify the validity of the model. First, it examines the case with different values for the CRRA coefficient to see the sensitivity of equilibrium term premiums with respect to the value of risk aversion. Second, it examines the effect of habit formation for household's consumption. In this case, the household's value function changes to,

$$
V_{t}=\left\{\left(c_{t}-h c_{t-1}\right)^{1-\sigma}+\beta \mathbb{E}_{t}\left[V_{t+1}^{1-\alpha}\right]^{\frac{1-\sigma}{1-\alpha}}\right\}^{\frac{1}{1-\sigma}}
$$

where $h$ is set to 0.25 based on the previous literature. It is an important robustness check because the habit formation is considered one of driving forces for risk premiums in the asset pricing literature. Third, it examines the case with fixed trend inflation. This change may affect the average shape of yield curve because the analysis in the main text shows that the volatility of long term interest rates is quite different between the case of time varying trend inflation and fixed trend inflation. Fourth and finally, it examines what if the monetary policy responds to income gap $y_{t}$ in addition to inflation gap $\pi_{t}$. That is, the monetary policy rule in this case changes to,

$$
R_{t}=R_{t-1}^{\phi_{r}}\left[\pi_{t}^{*} g^{*}\left(\frac{\Pi_{t}}{\pi_{t}^{*}}\right)^{\phi_{\pi}}\left(\frac{Y_{t}}{y_{t}^{*}}\right)^{\phi_{y}}\right]^{1-\phi_{r}}
$$

In all cases, I check the robustness only for the US equilibrium yield curve by changing a part of specifications and examining the marginal change from the baseline result.

Figure 7 shows the result of the robustness checks. All charts in this figure show that the main result is robust to those changes: The model can replicate the positive and sizable term premiums under the estimated inflation and income co-movement. Some comments are in order. First, while the size of term premiums is highly sensitive to the CRRA coefficient as expected, the qualitative result of positive and sizable term premiums is preserved for a relatively wide range of CRRA coefficients. Second, while the very small effects of habit formation on term premiums are in contrast with the previous finance literature including Wachter (2006), the mechanism behind the small effects of habit formation is similar to Rudebusch and Swanson (2008). As they argue, the effects of habit formation are small if the household can smooth its consumption in response to negative 
shocks to income. In the face of the negative shock, the household can smooth consumption by adjusting the labor supply in their model and the amount of savings in the present model, both of which leading to very small effects of habit formation. Third, the time varying trend inflation barely affects the size of term premiums because it is very slow-moving with very small volatility, thus generating any risks for consumers over the business cycle. Fourth, when the central bank responds to income gap, the size of term premiums is barely changed but become slightly higher than the baseline. This is because higher interest rates (lower bond prices) suppress consumption growth, thus reinforcing the negative correlation between bond prices and consumption growth. 
Figure 1: Phillips Curve in the Stochastic Trend Model: $\log \left(y_{t}\right)$ and $\log \left(\pi_{t}\right)$
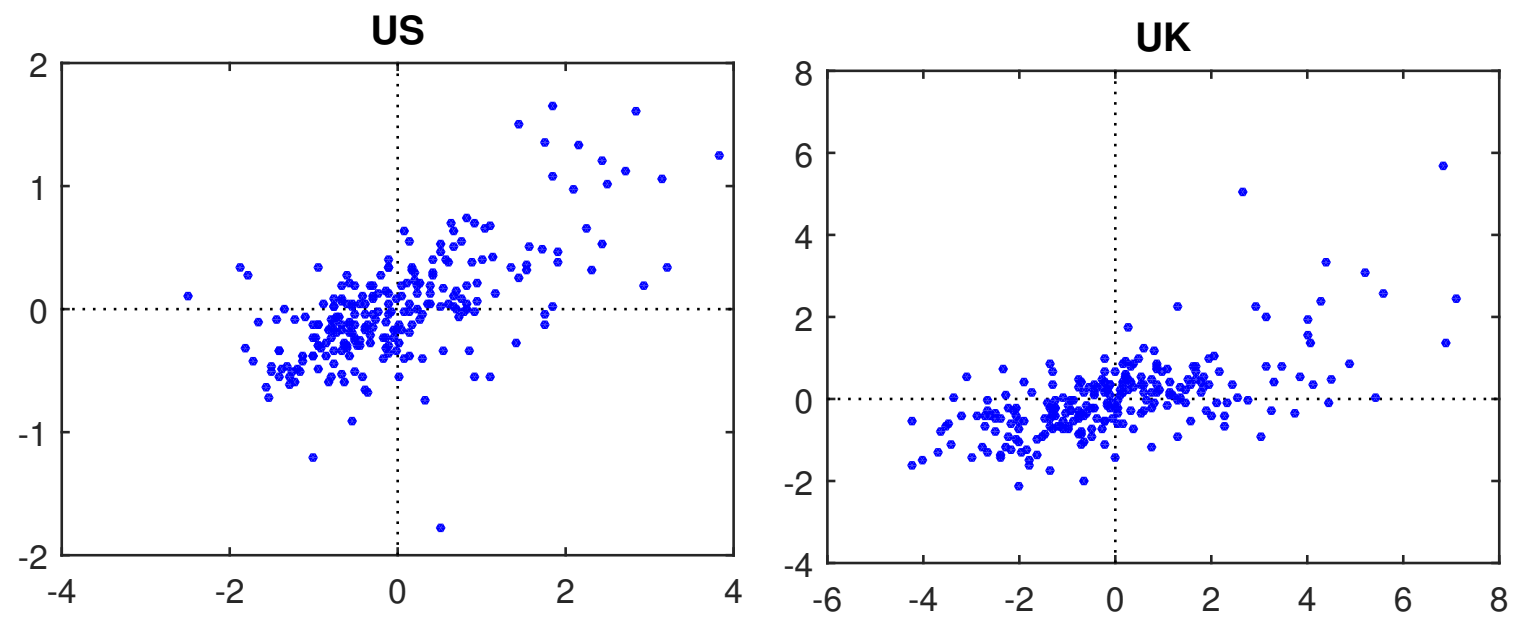

Note: This figure shows the scatter plots for estimated inflation gaps and income gaps in the stochastic trend model.

Figure 2: Long-run Income Growth and Inflation: $\log \left(g_{t}\right)$ and $\log \left(\pi_{t}\right)$
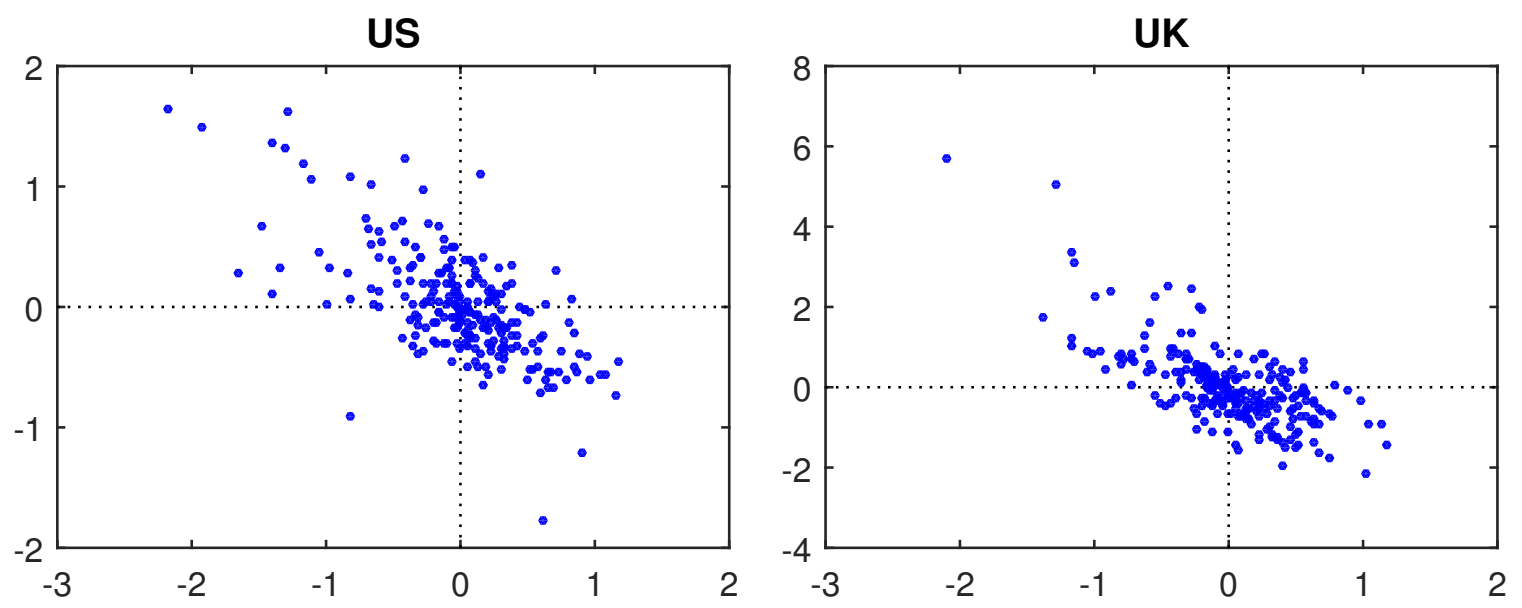

Note: This figure shows the scatter plots for estimated inflation gaps and growth of long-run income in the stochastic trend model. 
Table 1: Estimation Results

\begin{tabular}{|c|c|c|c|c|c|}
\hline \multirow{3}{*}{ Name } & \multirow{3}{*}{ Prior } & \multicolumn{4}{|c|}{ Posterior } \\
\hline & & \multicolumn{2}{|c|}{ Stochastic trend } & \multicolumn{2}{|c|}{ Trend stationary } \\
\hline & & US & UK & US & UK \\
\hline \multirow[t]{2}{*}{$\rho_{g}$} & Beta & 0.53 & 0.59 & - & - \\
\hline & $(0.50,0.25)$ & {$[0.36,0.71]$} & {$[0.38,0.82]$} & - & - \\
\hline \multirow[t]{2}{*}{$\rho_{\pi \pi}$} & Beta & 0.49 & 0.48 & 0.58 & 0.56 \\
\hline & $(0.50,0.25)$ & {$[0.33,0.66]$} & {$[0.37,0.59]$} & {$[0.49,0.69]$} & {$[0.46,0.65]$} \\
\hline \multirow[t]{2}{*}{$\rho_{\pi y}$} & Uniform & 0.14 & 0.17 & 0.06 & 0.15 \\
\hline & $(-1,1)$ & {$[0.02,0.26]$} & {$[0.10,0.23]$} & {$[0.03,0.09]$} & {$[0.11,0.19]$} \\
\hline \multirow[t]{2}{*}{$\rho_{y \pi}$} & Uniform & 0.34 & 0.34 & -0.16 & -0.05 \\
\hline & $(-1,1)$ & {$[0.04,0.63]$} & {$[0.08,0.59]$} & {$[-0.34,0.03]$} & {$[-0.22,0.10]$} \\
\hline \multirow[t]{2}{*}{$\rho_{y y}$} & Beta & 0.79 & 0.77 & - & - \\
\hline & $(0.80,0.05)$ & {$[0.71,0.88]$} & {$[0.69,0.85]$} & - & - \\
\hline \multirow[t]{2}{*}{$\rho_{y y}$} & Beta & - & - & 0.84 & 0.65 \\
\hline & $(0.50,0.25)$ & - & - & {$[0.78,0.90]$} & {$[0.57,0.73]$} \\
\hline \multirow[t]{2}{*}{$\rho_{\xi}$} & Beta & 0.95 & 0.96 & 0.97 & 0.97 \\
\hline & $(0.95,0.03)$ & {$[0.92,0.99]$} & {$[0.92,0.99]$} & {$[0.96,0.99]$} & {$[0.95,0.99]$} \\
\hline \multirow[t]{2}{*}{$\sigma_{y y}$} & Inv.Gamma & 0.26 & 1.71 & 0.49 & 1.86 \\
\hline & $(0.4$, Inf $)$ & {$[0.16,0.36]$} & {$[1.36,2.09]$} & {$[0.41,0.56]$} & {$[1.50,2.02]$} \\
\hline \multirow[t]{2}{*}{$\sigma_{\pi \pi}$} & Inv.Gamma & 0.11 & 0.45 & 0.11 & 0.45 \\
\hline & (0.3,Inf) & {$[0.09,0.13]$} & {$[0.37,0.53]$} & {$[0.09,0.13]$} & {$[0.38,0.51]$} \\
\hline \multirow[t]{2}{*}{$\sigma_{g g}$} & Inv.Gamma & 0.27 & 0.29 & - & - \\
\hline & $(0.3$, Inf $)$ & {$[0.13,0.40]$} & {$[0.08,0.51]$} & - & - \\
\hline \multirow[t]{2}{*}{$\sigma_{\pi y}$} & Uniform & 0.31 & 0.02 & -0.13 & -0.19 \\
\hline & $(-1,1)$ & {$[0.00,0.61]$} & {$[-0.17,0.23]$} & {$[-0.24,-0.03]$} & {$[-0.29,-0.09]$} \\
\hline \multirow[t]{2}{*}{$\sigma_{\pi g}$} & Uniform & -0.51 & -0.63 & - & - \\
\hline & $(-1,1)$ & {$[-0.79,-0.22]$} & {$[-0.98,-0.30]$} & - & - \\
\hline
\end{tabular}

Note: This table shows the prior distributions and the estimated posterior mean and 90 percent confidence intervals. Inflation series in each country are US: PCE deflator (chain price index) and UK: Long Term Price Indicator of Consumer Goods and Services. Also, the real income data for US and UK are taken from the national statistics. The sample periods are 1959Q2 - 2017Q4 for US and 1957Q2 - 2017Q4 for UK. 
Figure 3: Phillips Curve in the Trend Stationary Model: $\log \left(y_{t}\right)$ and $\log \left(\pi_{t}\right)$
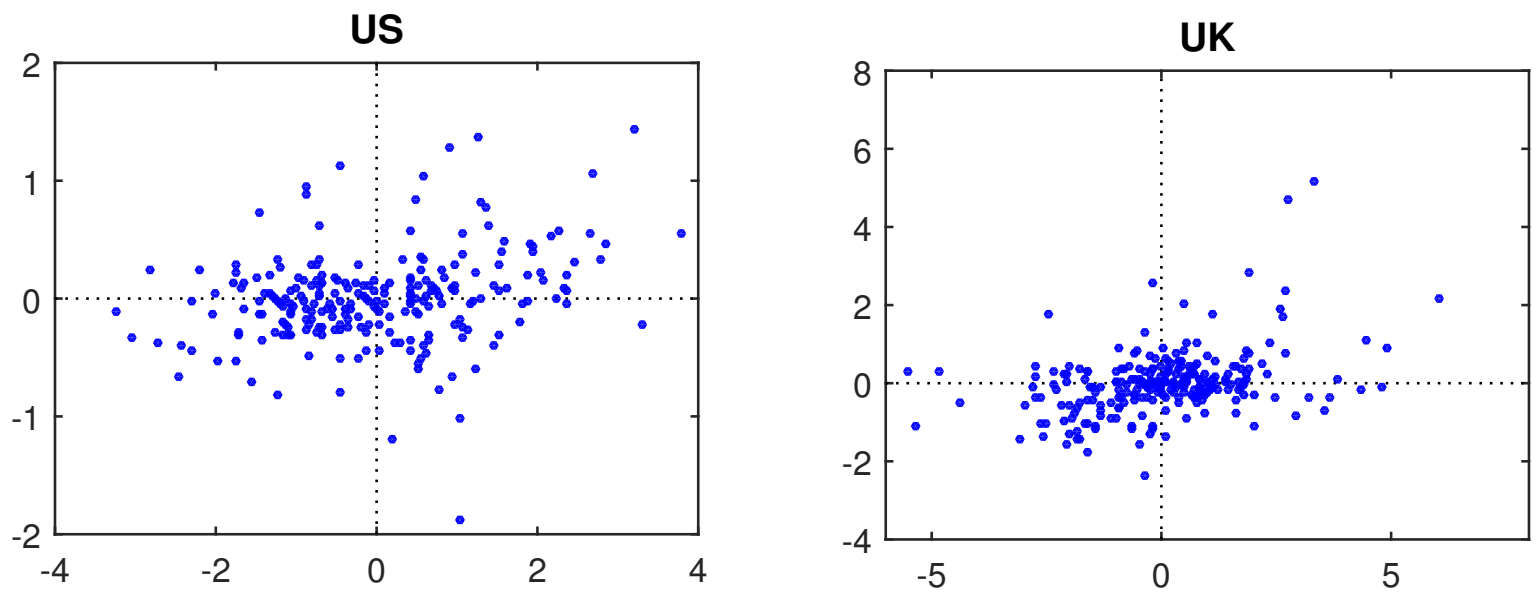

Note: This figure shows the scatter plots for estimated inflation gaps and income gaps in the trend stationary model.

Table 2: Calibration Values

\begin{tabular}{ll}
\hline \hline Parameters & Values \\
\hline Discount rate, $\beta$ & 0.9985 \\
Inverse of IES, $\sigma$ & 2.0 \\
Risk averseness, $\alpha$ & 40 for US and 20 for UK \\
Cost for bond holdings, $\phi_{b}$ & 0.001 \\
Steady-state savings, $b^{*}$ & 4.8 \\
Response to inflation, $\phi_{\pi}$ & 2.0 for US and 1.0 for UK \\
Interest rate smoothing, $\phi_{r}$ & 0.8 \\
\hline
\end{tabular}


Table 3: Stylized Facts: Shape of yield curves in US and UK

\begin{tabular}{ccccccccc}
\hline \hline & \multicolumn{3}{c}{ Average Level } & & \multicolumn{3}{c}{ Standard Deviation } \\
\cline { 2 - 4 } \cline { 7 - 8 } & $\mathrm{O} / \mathrm{N}$ & $5 \mathrm{Y}$ & $10 \mathrm{Y}$ & & $\mathrm{O} / \mathrm{N}$ & $5 \mathrm{Y}$ & $10 \mathrm{Y}$ \\
\hline U.S. & 5.13 & 5.87 & 6.20 & & 3.63 & 3.04 & 2.82 \\
$(1959 Q 2-2017 \mathrm{Q} 1)$ & $(0.00)$ & $(0.74)$ & $(1.07)$ & & $(1.00)$ & $(0.83)$ & $(0.77)$ \\
\hline U.K. & 6.18 & 7.32 & 7.65 & & 4.00 & 3.82 & 3.62 \\
$(1957 Q 2-2017 \mathrm{Q} 1)$ & $(0.00)$ & $(0.51)$ & $(0.84)$ & & $(1.00)$ & $(0.96)$ & $(0.91)$ \\
\hline
\end{tabular}

Note: The table shows the average shape of yield curve and the volatility of interest rates for each maturity in US and UK. The table is based on the data for government bonds in each maturity for 1959Q1-2017Q1 for US and 1957Q1$2017 \mathrm{Q} 1$ for UK. The values in parentheses for the average levels are the spreads relative to the short-term interest rates (i.e., term premiums for 5-year and 10-year bonds), and those for the volatility are the volatility of long-term interest rates relative to the volatility of short-term interest rates.

Figure 4: Equilibrium Yield Curve in the Simulated Model
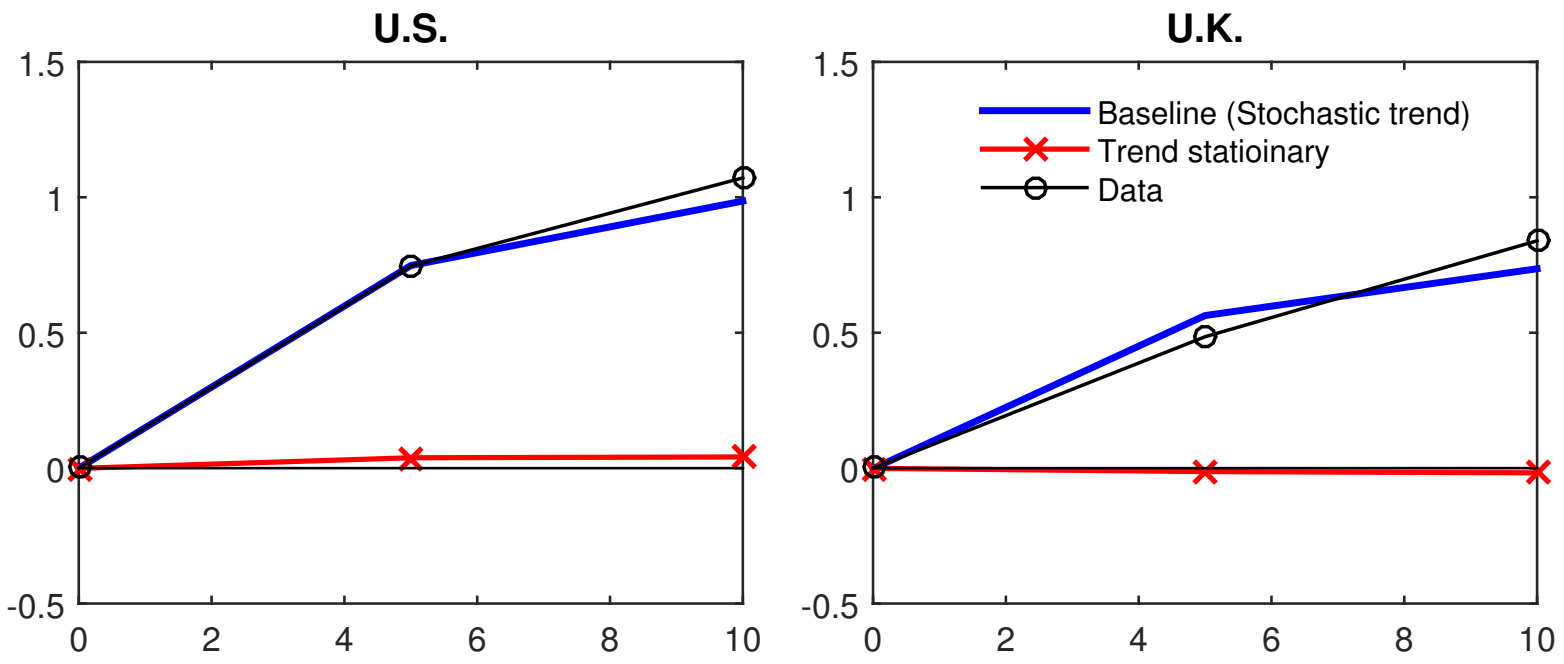

Note: The bold blue lines and the red lines with x-marks show the equilibrium yield curves in the baseline case (stochastic trend model) and the trend stationary model, respectively, with $\alpha=40$ for US and $\alpha=20$ for UK. The thin black lines with circles show the average term spreads in data for 1959Q1-2017Q1 for US and 1957Q1-2017Q1 for UK. 
Table 4: Equilibrium Yield Curve in US and UK

\begin{tabular}{|c|c|c|c|c|}
\hline & \multicolumn{2}{|c|}{ U.S. } & \multicolumn{2}{|c|}{ U.K. } \\
\hline & 5 -year & 10-year & 5 -year & 10-year \\
\hline \multicolumn{5}{|l|}{ I. Data } \\
\hline Nominal term premium & 0.75 & 1.07 & 0.49 & 0.84 \\
\hline \multicolumn{5}{|l|}{ II. Model } \\
\hline Nominal term premium & 0.75 & 0.99 & 0.56 & 0.74 \\
\hline Real term premium & 0.48 & 0.66 & 0.16 & 0.26 \\
\hline \multicolumn{5}{|l|}{ III. Model (Low-for-Long) } \\
\hline Nominal term premium & 0.46 & 0.64 & 0.31 & 0.41 \\
\hline Real term premium & 0.08 & 0.19 & -0.12 & -0.10 \\
\hline
\end{tabular}

Note: This table shows the equilibrium nominal and real term premiums along with the average term spread for 5-year and 10-year government bonds. The last two rows show the nominal and real term premium for the low-for-long economy in the counterfactual simulation.

Figure 5: Equilibrium Yield Curve with Different Monetary Policy Rules
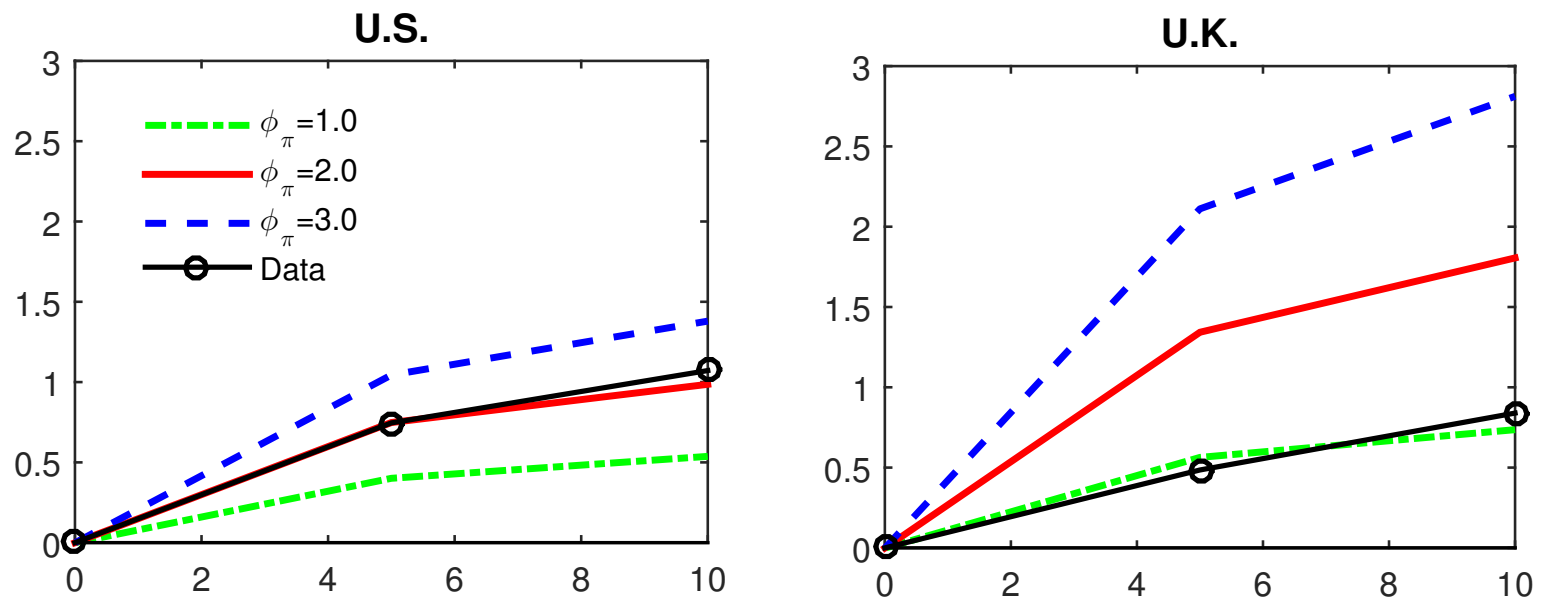

Note: This figure shows the equilibrium yield curves with different degrees of monetary policy responses to inflation. The green dot-dashed line, the bold red line, and the dashed blue line show the case of a low, medium, and high degree of response to inflation $\left(\phi_{\pi}=1.0,2.0\right.$ and 3.0). 
Table 5: Volatility of Nominal Interest Rate Relative to Inflation Volatility

\begin{tabular}{ccccc}
\hline \hline & Data & \multicolumn{3}{c}{ Model } \\
\cline { 3 - 5 } & & $\phi_{\pi}=1.0$ & $\phi_{\pi}=2.0$ & $\phi_{\pi}=3.0$ \\
\hline US & 1.43 & 0.69 & 1.26 & 2.08 \\
UK & 0.80 & 0.81 & 1.37 & 2.06 \\
\hline
\end{tabular}

Note: The table shows the volatility of short-term nominal interest rate relative to inflation volatility in US and UK. The table is based on the data for 1959Q1-2017Q1 for US and 1957Q1-2017Q1 for UK.

Figure 6: Relative Volatility for Each Maturity
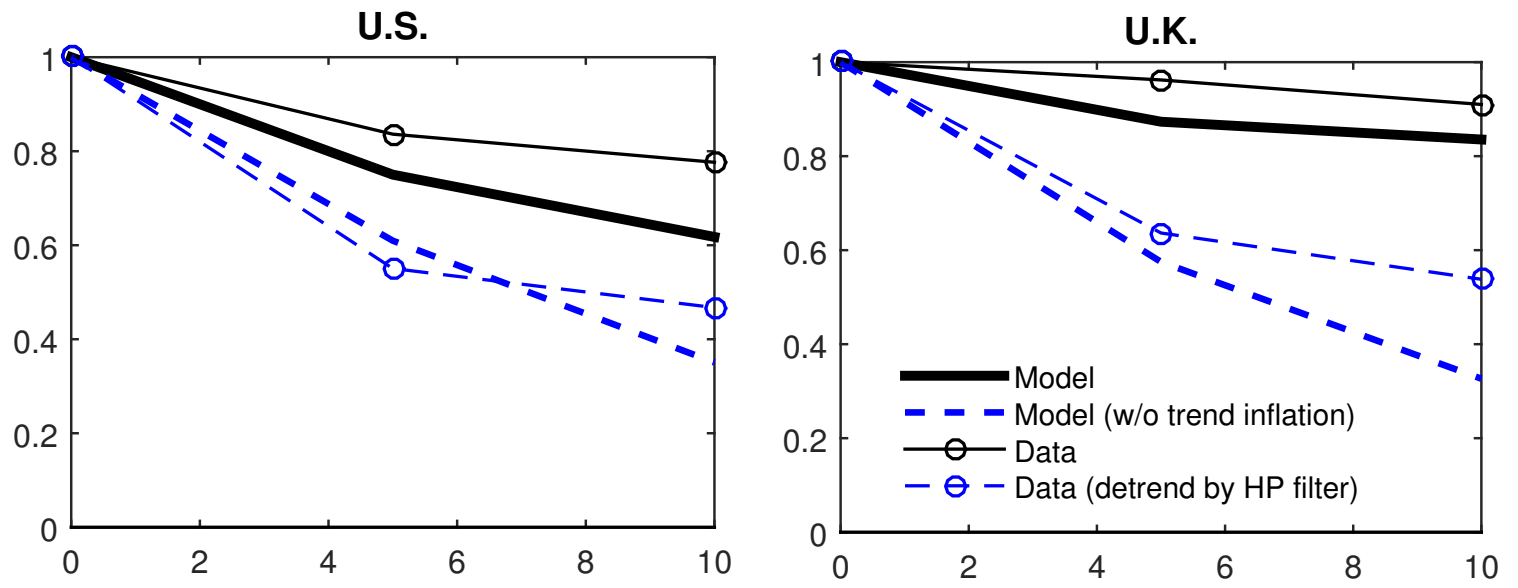

Note: This figure shows volatility of long-term interest rates relative to volatility of short-term interest rates in data and the model. The thick bold lines show the case of time varying trend inflation (baseline) while the dashed lines show the case of fixed trend inflation. Also, the thin bold lines with circles show the relative volatility in data while the dashed lines with circles show the relative volatility for interest rates detrended by the HP filter. 
Table 6: Macroeconomic Moments for Consumption Growth

\begin{tabular}{lllllll}
\hline \hline & & \multicolumn{2}{c}{ U.S. } & & \multicolumn{2}{c}{ U.K. } \\
\cline { 3 - 4 } \cline { 6 - 7 } & & Model & Data & & Model & Data \\
\hline \multirow{2}{*}{ Quarterly growth } & $\operatorname{std}\left(\Delta c_{t}\right)$ & 1.03 & 0.67 & & 1.03 & 1.06 \\
& $\operatorname{corr}\left(\Delta c_{t}, \Delta y_{t}\right)$ & 0.46 & 0.53 & & 0.59 & 0.29 \\
& $\operatorname{corr}\left(\Delta c_{t}, \pi_{t}\right)$ & -0.66 & -0.36 & & -0.68 & -0.36 \\
& $\operatorname{corr}\left(\Delta c_{t-1}, \Delta c_{t}\right)$ & 0.11 & 0.32 & & 0.23 & -0.06 \\
\hline Yearly growth & $\operatorname{std}\left(\Delta c_{t}\right)$ & 0.59 & 0.47 & & 0.62 & 0.57 \\
& $\operatorname{corr}\left(\Delta c_{t}, \Delta y_{t}\right)$ & 0.54 & 0.77 & & 0.64 & 0.65 \\
& $\operatorname{corr}\left(\Delta c_{t}, \pi_{t}\right)$ & -0.57 & -0.53 & & -0.61 & -0.49 \\
\hline 2-year growth & $\operatorname{std}\left(\Delta c_{t}\right)$ & 0.43 & 0.39 & & 0.46 & 0.46 \\
& $\operatorname{corr}\left(\Delta c_{t}, \Delta y_{t}\right)$ & 0.54 & 0.82 & & 0.70 & 0.73 \\
& $\operatorname{corr}\left(\Delta c_{t}, \pi_{t}\right)$ & -0.55 & -0.58 & & -0.53 & -0.56 \\
\hline
\end{tabular}

Note: This table shows macroeconomic moments for quarterly, yearly, and 2-year consumption growth. 
Figure 7: Equilibrium Yield Curve in a Different Setting
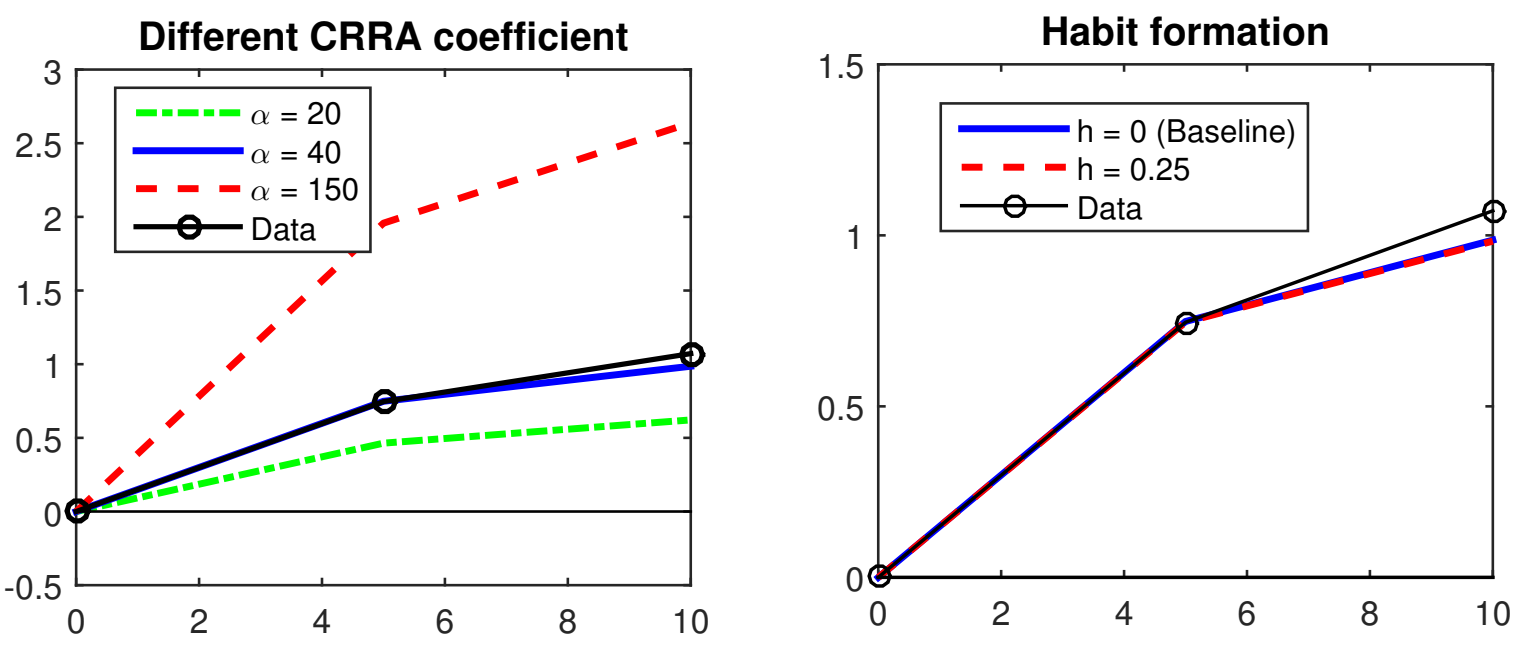

Trend inflation
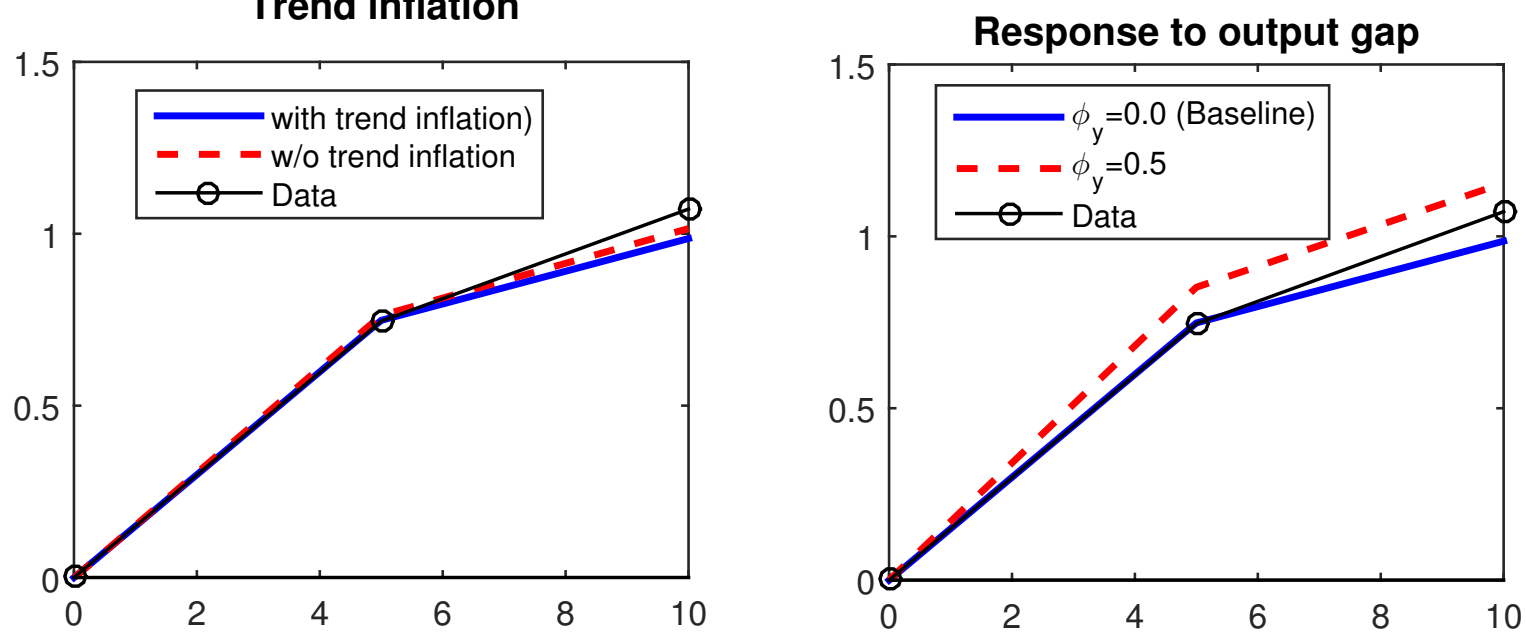

Note: The figure shows the result of four robustness checks: Different values of the CRRA coefficient, the household with habit formation, the case without trend inflation, and the monetary policy rule responding to output gap. For all cases, the figure shows only the US case along with the baseline. 